\title{
Differential Associative Training Enhances Olfactory Acuity in Drosophila melanogaster
}

\author{
Jonas Barth, ${ }^{\star}$ Shubham Dipt, ${ }^{\star}$ Ulrike Pech, Moritz Hermann, Thomas Riemensperger, and André Fiala \\ Georg-August-University Göttingen, Johann-Friedrich-Blumenbach-Institute for Zoology and Anthropology, Molecular Neurobiology of Behavior, 37077 \\ Göttingen, Germany
}

\begin{abstract}
Training can improve the ability to discriminate between similar, confusable stimuli, including odors. One possibility of enhancing behaviorally expressed discrimination (i.e., sensory acuity) relies on differential associative learning, during which animals are forced to detect the differences between similar stimuli. Drosophila represents a key model organism for analyzing neuronal mechanisms underlying both odor processing and olfactory learning. However, the ability of flies to enhance fine discrimination between similar odors through differential associative learning has not been analyzed in detail. We performed associative conditioning experiments using chemically similar odorants that we show to evoke overlapping neuronal activity in the fly's antennal lobes and highly correlated activity in mushroom body lobes. We compared the animals' performance in discriminating between these odors after subjecting them to one of two types of training: either absolute conditioning, in which only one odor is reinforced, or differential conditioning, in which one odor is reinforced and a second odor is explicitly not reinforced. First, we show that differential conditioning decreases behavioral generalization of similar odorants in a choice situation. Second, we demonstrate that this learned enhancement in olfactory acuity relies on both conditioned excitation and conditioned inhibition. Third, inhibitory local interneurons in the antennal lobes are shown to be required for behavioral fine discrimination between the two similar odors. Fourth, differential, but not absolute, training causes decorrelation of odor representations in the mushroom body. In conclusion, differential training with similar odors ultimately induces a behaviorally expressed contrast enhancement between the two similar stimuli that facilitates fine discrimination.
\end{abstract}

Key words: associative learning; Drosophila melanogaster; odor discrimination; olfaction; optical calcium imaging; sensory processing

\section{Introduction}

Most animals are able to detect, differentiate, and learn odors as indicators for food, mating partners, or hazardous substances. The fruit fly, Drosophila melanogaster, represents a key model organism for the analysis of genetic and neuronal mechanisms underlying odor detection and odor processing (Vosshall and Stocker, 2007). Moreover, Drosophila is widely used for investigating the neuronal basis of associative olfactory learning (Davis, 1993; Heisenberg, 2003; Fiala, 2007). Fruit flies detect odors with olfactory sensory neurons (OSNs) located on the third antennal segments and maxillary palps (Vosshall and Stocker, 2007). Each OSN expresses one or very few specific olfactory receptors, and

\footnotetext{
Received June 19, 2013; revised Dec. 13, 2013; accepted Dec. 17, 2013.

Author contributions: J.B., S.D., and A.F. designed research; J.B., S.D., U.P., M.H., and T.R. performed research; J.B., S.D., U.P., M.H., T.R., and A.F. analyzed data; J.B., U.P., T.R., and A.F. wrote the paper.

This work was supported by the German Research Foundation (FI 821/2-1, Fl 821/3-1, SPP 1392, and SFB 889/B04 and (02), the German Ministry of Education and Research via the Bernstein Center for Computational Neuroscience Göttingen) Grant 01GQ1005A, and the Göttingen Graduate School for Neurosciences, Biophysics and Molecular Biosciences. We thank Serge Birman, Silke Sachse, Hiromu Tanimoto, and the Bloomington stock center for providing fly strains; Veit Grabe and Silke Sachse for their help; and Hiromu Tanimoto and his laboratory members for technical advice.

The authors declare no competing financial interests.

*J.B. and S.D. contributed equally to this work.

Correspondence should be addressed to Dr. André Fiala, Georg-August-University Göttingen, Johann-FriedrichBlumenbach-Institute for Zoology and Anthropology, Molecular Neurobiology of Behavior, Julia-Lermontowa-Weg 3, 37077 Göttingen, Germany. E-mail: afiala@gwdg.de.

DOI:10.1523/JNEUROSCI.2598-13.2014

Copyright $\odot 2014$ the authors $\quad 0270-6474 / 14 / 341819-19 \$ 15.00 / 0$
}

those OSNs that express the same receptors converge onto the same glomeruli in the antennal lobes (Vosshall and Stocker, 2007). The glomeruli are interconnected by local interneurons (Chou et al., 2010; Seki et al., 2010) that have been implicated in gain control (Olsen and Wilson, 2008; Root et al., 2008), temporal synchronization, and decorrelation of odor-evoked activity (Wilson et al., 2004; Wilson and Laurent, 2005). They have also been hypothesized to facilitate fine discrimination of similar odors (Wilson and Laurent, 2005). Olfactory projection neurons convey the odor information to the lateral horn and the mushroom body (Tanaka et al., 2004), a brain region critical for associative olfactory learning (Heisenberg, 2003).

Odor concentration and composition are often variable in time and space. This confronts the animal with a source of uncertainty about odor identity and, hence, possible relevance. To solve the problem of assigning relevance to variable stimuli, animals are able to generalize (i.e., to transfer a learned behavioral response to stimuli that are similar yet slightly different from a cue experienced as rewarding or punishing) (Pavlov, 1927; Guttman and Kalish, 1956; Ghirlanda and Enquist, 2003). The degree to which animals generalize across stimuli can be regarded as to which degree these are perceived as similar or distinct (Shepard, 1987; Pearce, 1994; Guerrieri et al., 2005; Niewalda et al., 2011). Perceptual similarity is, however, subject to experience. In some instances, it is advantageous for the animal to learn to differentiate precisely a relevant stimulus from a physically similar, but 
irrelevant, one. Enhanced behaviorally expressed discriminability between similar odors, which is referred to as olfactory acuity (Wilson and Stevenson, 2006), can be induced by differential associative learning in the course of which a conditioned stimulus $\left(\mathrm{CS}^{+}\right)$is reinforced by punishment or reward; a second, similar stimulus $\left(\mathrm{CS}^{-}\right)$is explicitly not reinforced (Pavlov, 1927; Hanson, 1959; Giurfa, 2004; Mishra et al., 2010). The ability to shift olfactory discrimination from generalizing across to differentiating between similar odors has been demonstrated in many species (Bitterman et al., 1983; Cleland et al., 2002; Fletcher and Wilson, 2002; Li et al., 2008; Mishra et al., 2010; Chapuis and Wilson, 2011; Chen CF et al., 2011). In Drosophila, however, it remains unclear whether differential training with similar odors enhances olfactory acuity as to facilitate distinction between them. We addressed this question using chemically similar odorants and analyzed the experience-dependent, relative change in perceptual similarity caused by differential training.

\section{Materials and Methods}

Drosophila strains and fly husbandry. Flies were raised on standard cornmeal medium at $25^{\circ} \mathrm{C}, 60 \%$ humidity, and a light/dark cycle of $12 \mathrm{~h} / 12 \mathrm{~h}$. The flies were raised in plastic vials containing $\sim 30 \mathrm{ml}$ medium with $\sim 200-300$ animals per vial and were transferred to fresh vials every 2-3 d. All behavioral experiments were performed between 1.5 and $10.5 \mathrm{~h}$ Zeitgebertime, ensuring controlled circadian conditions. Wild-type flies of the Canton-S strain were used if not stated otherwise, and the feeding status was equal throughout all experiments. For targeting local interneurons in the antennal lobe, the Gal4-enhancer-trap lines NP1227 and NP2426 (Sachse et al., 2007) were used. For visualizing these neurons, the flies were crossed with flies homozygous for both UAS-mCD8GFP and UAS-syb-GFP, kindly provided by S. Birman. For blocking synaptic transmission, a fly strain with two copies of the temperature sensitive shibire $^{\text {ts }}$ allele on the X-chromosome and the third chromosome under control of UAS was used (Kitamoto, 2001). For monitoring $\mathrm{Ca}^{2+}$ activity in olfactory sensory neurons or olfactory projection neurons, respectively, flies homozygous for Or83b-Gal4 (Wang et al., 2003) or GH146-Gal4 (Stocker et al., 1997) and UAS-GCaMP3.0 (Tian et al., 2009) were used. For monitoring $\mathrm{Ca}^{2+}$ activity in the mushroom body, GCaMP3.0 was expressed under direct control of the mb247-promoter (Pech et al., 2013).

Learning assays. For associative olfactory learning, groups of $\sim 100$ flies (5-9 d old) were trained as described by Tully and Quinn (1985) with modifications: four experiments were performed simultaneously in a modified learning apparatus described by Schwaerzel et al. (2002). A constant airflow of $\sim 167 \mathrm{ml} / \mathrm{min}$ in each training tube assured a constant odor flow inside the training tubes. The experiments were performed at diffuse light conditions and at a relative humidity of $60-80 \%$. Experimental groups were tested in parallel in a pseudo-randomized way, and flies were stringently controlled for their feeding status. To block synaptic transmission using UAS-shibire ${ }^{\text {ts }}$ flies, the temperature was adjusted to $31-33^{\circ} \mathrm{C}$. All other experiments were performed at $24-26^{\circ} \mathrm{C}$. Before each experiment, flies were transferred to empty vials and kept for $10 \mathrm{~min}$ at the respective temperature before the onset of the experiment. The odors 4-methylcyclohexanol (MCH), 3-octanol (3-Oct), 1-octen-3-ol (1-Oct), pentyl acetate (PA), and butyl acetate (BA) were purchased from SigmaAldrich and diluted in mineral oil. Training started 1 min after transferring the flies into training tubes each covered inside with an electrifiable grid. Each odor was presented for $1 \mathrm{~min}$ with a $1 \mathrm{~min}$ break between two odor applications. One odor $\left(\mathrm{CS}^{+}\right)$was temporally paired with 12 electric shocks of $90 \mathrm{~V}$ DC ( $1.25 \mathrm{~s}$ shock and $3.75 \mathrm{~s}$ interpulse intervals). The second odor $\left(\mathrm{CS}^{-}\right)$was presented without shocks. After another minute, the flies were transferred to the T-maze part of the apparatus with both odors presented from each side, and flies were tested for their odor preference for $2 \mathrm{~min}$. Subsequently, the flies were counted and a preference index was calculated by subtracting the number of flies on the side of the $\mathrm{CS}^{-}$from the number of flies on the side of the $\mathrm{CS}^{+}$, divided by the total number of flies. A learning index was calculated by averaging the absolute preference indices from two reciprocal experiments.

Climbing assay. For each trial, ten 6-8 d old flies were transferred into a $27-\mathrm{cm}$-long $10 \mathrm{ml}$ serological pipette without anesthesia and left to rest for $10 \mathrm{~min}$ at the appropriate temperature $\left(32-33^{\circ} \mathrm{C}\right.$ or $24.5-25.5^{\circ} \mathrm{C}$, respectively). After the resting period, the flies were tapped to the bottom of the pipette and were allowed to climb for $1 \mathrm{~min}$ before the number of flies was counted. A climbing index (CI) was calculated as CI $=0.5$ * $\left(n_{\text {total }}+n_{\text {up }}-n_{\text {down }}\right) / n_{\text {total, }}$, where $n_{\text {total }}$ is the total number of flies, $\mathrm{n}_{\text {up }}$ is the number of flies in the uppermost $7 \mathrm{~cm}$ part of the pipette, and $n_{\text {down }}$ is the number of flies in the lowermost $7 \mathrm{~cm}$. The experiment was repeated three times per trial, and the mean CI was used as an indicator of locomotor performance.

Shock avoidance. Shock avoidance was assayed in the same training apparatus used for olfactory learning. One of the arms of the T-maze partition consisted of the training tube covered inside with the electrifiable grid. The flies were placed in the middle compartment between two arms of the T-maze. During the test of $1 \mathrm{~min}, 12$ electric shocks of $90 \mathrm{~V}$ DC (1.25 s shock and $3.75 \mathrm{~s}$ inter pulse intervals) were administered on one side and flies could distribute freely between the two sides. An avoidance index was calculated as the number of flies in the electrified tube minus the number of flies on the opposite side divided by the total number of flies.

Odor preference. Odor preference was assayed in the same training apparatus used for olfactory learning by placing the flies in the middle compartment between the two arms of the T-maze partition. One arm was equipped with an odor cup containing an odorant, whereas the odor cup on the other arm contained the solvent mineral oil. The flies were allowed to distribute for $2 \mathrm{~min}$. A preference index was calculated as the number of flies in the arm containing the odor minus the number of flies in the opposite arm of the T-maze divided by the total number of flies.

Functional calcium imaging. Female flies (3-5 d old) expressing the genetically encoded $\mathrm{Ca}^{2+}$ sensor GCaMP3.0 (Tian et al., 2009) were immobilized for $\sim 5 \mathrm{~min}$ on ice. A single fly was subsequently placed in a custom-built fly holder and fixed using adhesive tape. A piece of a razor blade and a blade holder were used to cut a window through the tape and the cuticle of the fly's head. After careful removal of fat bodies and tracheae, $1.5 \%$ low melting agarose solution (Sigma-Aldrich) diluted in Ringer's solution (5 mm HEPES, pH 7.4, $130 \mathrm{~mm} \mathrm{NaCl}, 5 \mathrm{~mm} \mathrm{KCl,} 2 \mathrm{~mm}$ $\mathrm{CaCl}_{2}, 2 \mathrm{~mm} \mathrm{MgCl}_{2}, 36 \mathrm{~mm}$ sucrose) of $<28^{\circ} \mathrm{C}$ was applied to the open head capsule. $\mathrm{Ca}^{2+}$ imaging was performed using an LSM 7 MP twophoton microscope (Carl Zeiss) equipped with a mode-locked Tisapphire Chameleon Vision II laser (Coherent), a 500-550 nm bandpass filter and a Plan-Apochromat $20 \times / 1.0$ NA water-immersion objective (Carl Zeiss). Attached to the microscope was a custom-built device to supply odorous air with a constant flow rate of $1 \mathrm{ml} / \mathrm{s}$ directly to the fly's antennae as described previously (Riemensperger et al., 2005.). Onset and duration of the odor stimulus were controlled using a customwritten LABVIEW program (National instruments). $\mathrm{Ca}^{2+}$ dynamics were monitored at an image acquisition rate of $5 \mathrm{~Hz}$ and an excitation wavelength of $920 \mathrm{~nm}$. For the measurements in olfactory sensory neurons, the odorants were presented three times each with a $20 \mathrm{~s}$ break between each stimulation, and data from three repetitive experiments were averaged for each fly. For measurements in olfactory projection neurons, which involved learning experiments, each odorant was presented only once with a $20 \mathrm{~s}$ break between each stimulation. In both olfactory sensory neurons and projection neurons, $\mathrm{Ca}^{2+}$ dynamics in the antennal lobe was measured in three different focal planes. Individual glomeruli were identified using optical sections and a 3D model of the glomerular structure of the antennal lobe (Laissue et al., 1999) available online in the fly brain atlas at http://www.flybrain.org (Armstrong et al., 1995) and by repeatedly comparing activity patterns across flies. Only those glomeruli that could be identified in all flies measured were further analyzed. The images were aligned to reduce small shifts in the X-Y direction using a custom written ImageJ plugin based on the TurboReg plugin (Thévenaz et al., 1998). The mean of five images before stimulus onset was used as baseline fluorescence $\left(\mathrm{F}_{0}\right)$. The difference in intensity $(\Delta \mathrm{F})$ was calculated by subtracting $\mathrm{F}_{0}$ from the fluorescence intensity value of each image $\left(\mathrm{F}_{\mathrm{i}}\right)$ and subsequently divided by the baseline fluo- 
rescence. Correlations between glomerular activity patterns evoked by odor pairs were calculated, and the maximal Pearson's correlation coefficient over the time course of the stimulation was determined for each fly and each odor pair. Measurements in the mushroom body were focused on the $\beta^{\prime}$ - and $\gamma$-lobe. The Amira 5.3.3 software (Visage Imaging) was used to reconstruct parts of the mushroom body from a $z$-stack covering several focal planes. For subjecting the animals to the training regimen under the microscope, flies were positioned onto two thin metal wires placed below the fly's thorax and subjected to 12 electric shock pulses of $90 \mathrm{~V}$ and $1.25 \mathrm{~s}$ with $3.75 \mathrm{~s}$ interpulse intervals. The temporal order of odor presentations and electric shocks was controlled using a customwritten LABVIEW program (National instruments). The images obtained from the mushroom body were aligned in the X-Y direction using a MATLAB program (MathWorks) to correct for slight movements (Guizar-Sicairos et al., 2008). For the pixel-based analysis, a KalmanFilter (Kalman, 1960) was subsequently applied to efficiently remove noise without losing spatial information. It should be noted that the Kalman filter altered the temporal dynamics of displayed $\mathrm{Ca}^{2+}$ transients. False-color-coded images were obtained by subtracting the image directly before stimulus onset from the image at the maximum of the intensity difference (i.e., at $2 \mathrm{~s}$ after odor onset) and divided by the baseline fluorescence. Noise was reduced using a mean filter with a 5 pixel range for the antennal lobe and a 1 pixel range for the mushroom body.

Immunohistochemistry. Brains and thoracic ganglia of 7- to 10-d-old flies were dissected in ice-cold Ringer's solution, fixed in 4\% paraformaldehyde for $2 \mathrm{~h}$ on ice, and subsequently washed three times for 20-30 min each at room temperature in PBS, $\mathrm{pH} 7.4$, containing $0.6 \%$ Triton $\mathrm{X}-100$ (PBT). After blocking in 2\% BSA dissolved in PBT for $2 \mathrm{~h}$ at room temperature, the samples were incubated overnight at $4^{\circ} \mathrm{C}$ with mouse anti-brp antibody (Wagh et al., 2006), diluted 1:5, and rabbit anti-GFP, diluted 1:5000 (Jackson ImmunoResearch Laboratories). After three washing steps in PBT for 20-30 min each at room temperature, the samples were incubated in 3\% normal goat serum diluted in PBT for 30 min. Subsequently, the preparations were incubated for $2 \mathrm{~h}$ at room temperature with the secondary antibodies diluted in PBT containing 3\% normal goat serum and 2\% BSA. The anti-rabbit Alexa488-conjugated antibody (Invitrogen) was diluted 1:100, the anti-mouse Cy3-conjugated antibody (Invitrogen) 1:250. Afterward, the brains were washed three times for 20-30 min each and kept in PBS at $4^{\circ} \mathrm{C}$ until they were mounted in Vectashield (Vector Laboratories). Confocal laser scanning microscopy was done using a Leica SP2 microscope equipped with a PlanApochromat $20 \times / 0.7$ NA objective. Maximum value projections across the $z$-direction were calculated across image stacks.

Statistical analysis. Groups of data were tested for normal distribution using the Shapiro-Wilk test. For comparisons across two normally distributed groups of data, the two-sample Student's $t$ test was applied; for testing for statistical significant differences from 0, the one-sample Student's $t$ test was used. For comparisons across more than two normally distributed groups of data, one-way ANOVA tests were used with subsequent Bonferroni-corrected post hoc comparisons. Dependent data were tested for significance using a one-way repeated-measures ANOVA and subsequent Bonferroni post hoc comparisons. For statistical comparisons between two non-normally distributed groups of data, the MannWhitney U test was used. Principal component analysis (PCA) was calculated using MATLAB (Mathworks). To quantify similarities between odor-evoked neuronal representations in the antennal lobe, Euclidean distances between odor-evoked, relative changes in fluorescence emission were calculated as follows: $\left(\sum\left(X_{i}-Y_{i}\right)^{2}\right)^{1 / 2}$, where $X_{i}$ and $Y_{i}$ are the fluorescence changes in the i-th glomerulus evoked by the odors $X$ and $Y$, respectively. Pearson's correlation coefficients between relative changes in fluorescence emission were determined as follows: $\operatorname{cov}(X, Y) /\left(\sigma_{x}, \sigma_{y}\right)$ where $X$ and $Y$ are two column vectors representing relative changes in fluorescence emission from all measured glomeruli evoked by two odors, cov is the covariance, and $\sigma_{x}$, and $\sigma_{y}$ are the standard deviations of $X$ and $Y$, respectively. In the mushroom body, Pearson's correlations between spatiotemporal $\mathrm{Ca}^{2+}$ dynamics evoked by odors were calculated based on pixels in defined regions of interest.

\section{Results}

\section{Generalization across two chemically and physiologically similar odors}

For our study, we chose two odorants, 3-Oct and 1-Oct, whose chemical structures differ only by one covalent bond (Fig. 1A). The odorant $\mathrm{MCH}$ serves as a chemically distinct odorant for comparison (Fig. 1A). We first determined the perceptual similarity between these odorants as expressed by the degree to which the animals generalize across them. Innate, naive preferences for the odors and their learnability are, however, often dependent on odorant concentration, and the flies' evaluation of odor quality can also be affected by the concentration (Masek and Heisenberg, 2008). To exclude potential effects of differential naive preference behavior, we first adjusted the respective odorant concentrations so that the flies' naive odor preferences were completely balanced. At the concentrations used throughout all experiments, the three odorants were slightly attractive to the animals, as indicated by positive preference indices (Fig. $1 B$ ). Because, in learning experiments, the animals were exposed to odors for $1 \mathrm{~min}$ with or without electric shock punishment, we tested whether the mere exposure to the odors would affect preference behavior, which was not the case $\left(F_{(2,45)}=0.03, p=0.96\right.$; one-way ANOVA). Behavioral adaptation due to $1 \mathrm{~min}$ odor exposure at the concentrations used could therefore be excluded. The diluent mineral oil did not evoke any behavioral response in a choice situation with blank air as alternative (Fig. $1 B$ ). In an absolute associative learning paradigm, we used either odor as a conditioned stimulus paired with electric shock punishment, or without any punishment, respectively. That is, the odor presentation was temporally paired with electric shocks $\left(\mathrm{CS}^{+}\right)$and the presentation of the diluent was not ("CS ${ }^{-”)}$. In a reciprocal group the diluent served as " $\mathrm{CS}^{+}$" and the odor as $\mathrm{CS}^{-}$(Fig. 1C). The absolute training procedure was combined thereby with a reciprocal experimental design to exclude nonassociative effects (Dudai, 1977). The animals acquired an equally strong aversion to the $\mathrm{CS}^{+}$after training with either odor $\left(F_{(2,45)}=0.4, p=0.68\right.$; one-way ANOVA), which reflects an equal learnability of all three odors used (Fig. $1 D)$. However, when the learning indices obtained in these reciprocal experiments were separated for those animals exposed to the odors as a $\mathrm{CS}^{+}$and those that were exposed to the odors as a $\mathrm{CS}^{-}$, strong learned odor avoidance was observed in those animals in which the odor has been paired with the punishment, as indicated by negative preference indices (Fig. $1 E$ ). In contrast, those animals that perceived the odor as a $\mathrm{CS}^{-}$still showed an attraction toward the odorant that was even slightly higher than the innate preference, although the increase in odor preference is statistically significant only for the odorant 3-Oct $\left(t_{(30)}=-5.1\right.$, $p<0.01)$, but not for 1 -Oct $\left(t_{(30)}=-1.3, p=0.19\right)$ and $\mathrm{MCH}$ $\left(t_{(30)}=-1.75, p=0.09\right.$; two-sample $t$ test) (Fig. $\left.1 F\right)$. Pairing the diluent mineral oil with electric shocks did not induce any learning $\left(t_{(15)}=-0.04, p=0.97\right.$; one sample $t$ test) (Fig. $\left.1 F\right)$, confirming that the diluent did not cause a behavioral response and is not learned as a stimulus. After balancing the concentration of the three odorants such that they induced equal innate preference and showed equal learnability, we tested whether flies could generalize across the odors presented. To do so, we reciprocally trained them with one odor as $\mathrm{CS}^{+}$or $\mathrm{CS}^{-}$, respectively, and tested for their response to the same or a novel odor in a choice situation. This "recognition experiment" revealed that training with either 1-Oct (Fig. 1G) or 3-Oct (Fig. 1H) in a reciprocal, absolute learning paradigm caused avoidance not only of the trained odor (gray bars), but also of the chemically similar odor 
A<smiles>COCOCCOC(=O)OCO</smiles><smiles>C=CC(O)OCOCOCO</smiles><smiles></smiles>

4-methylcyclohexanol

B
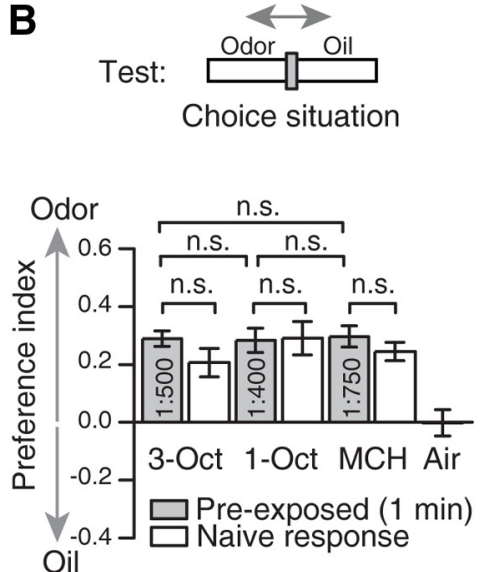

C

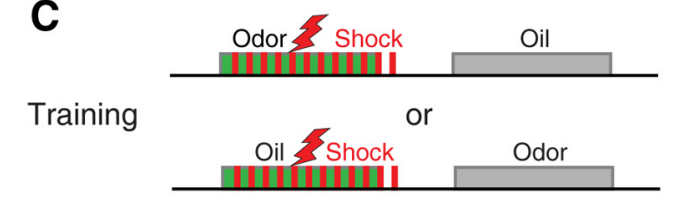

D

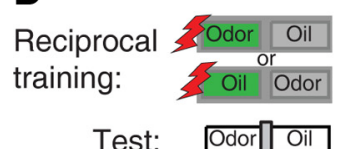

E

Training
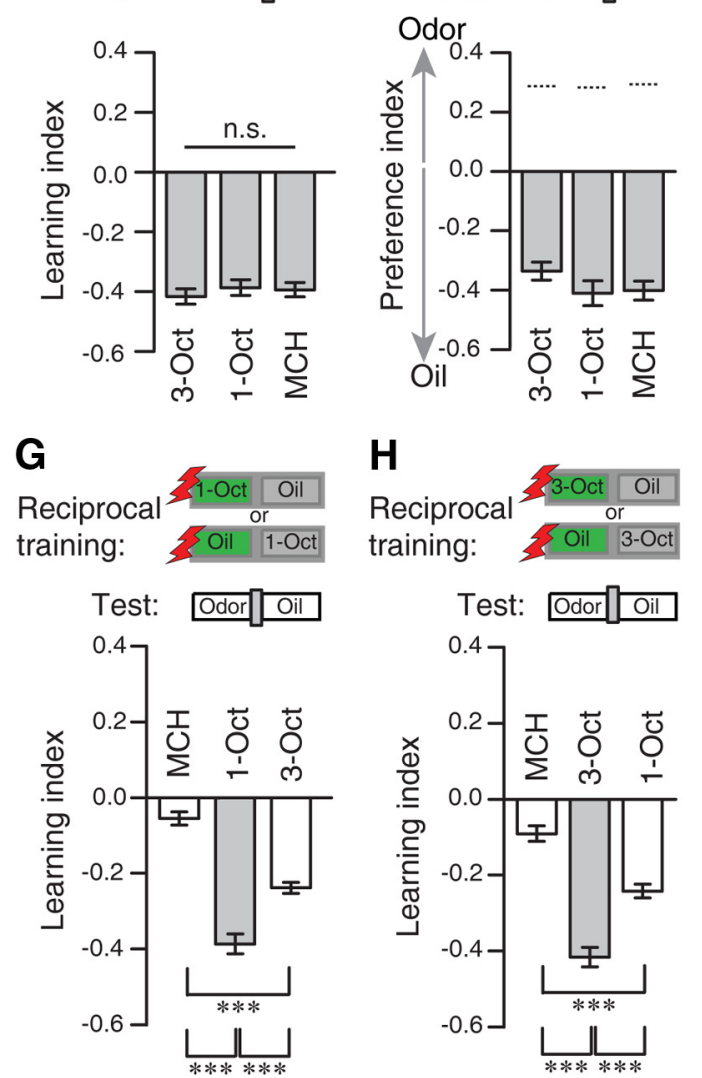

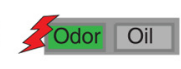

Test: Odor Oil

Test: Odor Oil

Choice situation

$\mathbf{F}$
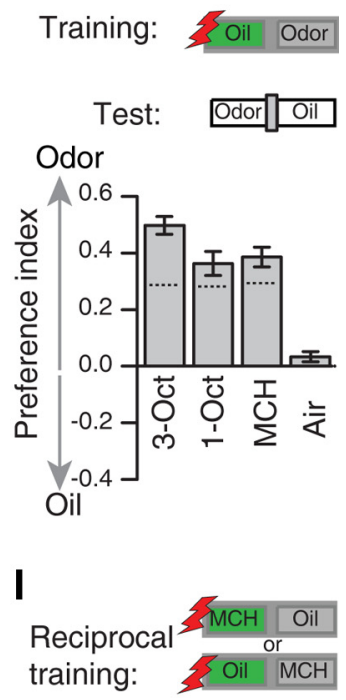

Test: Odor Oil

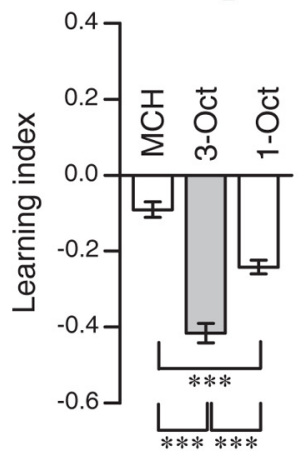

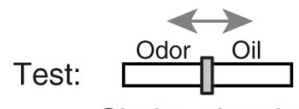

to a high degree (Fig. 1G: 1-Oct vs $\mathrm{MCH}$ : $t_{(30)}=-11.6, p<0.01 ; 3$-Oct vs MCH: $t_{(30)}=-6.4, p<0.01 ; 3$-Oct vs 1-Oct: $t_{(30)}$ $=5.2, p<0.01$; Figure $1 \mathrm{H}$ : 3-Oct vs MCH: $t_{(30)}=-10.7, p<0.01 ; 1-$ Oct vs $\mathrm{MCH}: t_{(30)}=-5.0, p<0.01 ; 1$-Oct vs 3-Oct: $t_{(30)}=5.7, p<0.01$; one-way ANOVA with Bonferroni post hoc tests). The dissimilar odor, $\mathrm{MCH}$, was only slightly avoided after training with 1-Oct or 3-Oct. Conversely, associative training with $\mathrm{MCH}$ did not cause any generalization when 1-Oct or 3-Oct was presented in the test situation (1-Oct vs MCH: $t_{(30)}$ $=-12.9, p<0.01 ; 1$-Oct vs 3 -Oct: $t_{(30)}=$ $0.4, p=1$; 3-Oct vs MCH: $t_{(30)}=-13.3$, $p<0.01$; one-way ANOVA with Bonferroni post hoc tests) (Fig. 1I). The chemical similarity/dissimilarity of the three odorants is therefore reflected in equivalent degrees of generalization.

To test for a potential physiological manifestation of odor similarity as expressed in behavior, we performed optical $\mathrm{Ca}^{2+}$ imaging experiments (Riemensperger et al., 2012) and monitored odor-

$\leftarrow$

(red boxes). Gray box represents odor or diluent stimulation without punishment. During the test, the trained flies were subjected to a choice situation between odor and mineral oil. $D$, Equal learnability of the three odors after absolute, reciprocal training. n.s., Not significant ( $p>0.05$; one-way ANOVA). Bars indicate mean $\pm \mathrm{SEM} ; n=16$ for each experiment. Either the odor or the diluent was temporally paired with electric shocks (gray boxes in the schematic illustrations). Negative learning indices indicate learned avoidance of the stimulus previously paired with the electric shocks. $\boldsymbol{E}$, Preference indices of animals subjected to an odor simultaneously with the electric shocks and the diluent without electric shocks. For comparison, the dotted lines indicate odor preferences of untrained animals that have been preexposed to the odors as shown in $\boldsymbol{B}$. The associative training caused an aversive behavior, indicated by negative preference indices. Bars indicate mean $\pm \mathrm{SEM} ; n=16$ for each experiment. $\boldsymbol{F}$, Preference indices of animals that have received electric shock stimulation simultaneously with the presentation of the diluent, but not during odor presentation. The dotted lines indicate odor preferences of untrained animals that have been preexposed to the odors as shown in $\boldsymbol{B}$. The training caused a slight increase in attractiveness compared with the naive preference, which is statistically significant only for 3-0ct (3-0ct: naive vs trained, $p<0.001$, two-sample $t$ test). Bars indicate mean \pm SEM; $n=16$ for each experiment. $\mathbf{G}-\mathbf{I}$, Absolute, reciprocal training of 1-0ct (G), 3-0ct $(\boldsymbol{H})$, and $\mathrm{MCH}(\boldsymbol{I})$ against the diluent mineral oil and test for the avoidance of each odor. In all cases, flies strongly avoided the trained odor (gray bars). Generalization was observed if flies were trained with either 1-0ct or 3-0ct and tested for the respective similar odor, but not if they were tested for the dissimilar odor $\mathrm{MCH}(\boldsymbol{G}, \boldsymbol{H})$. Flies did not generalize to 1-0ct or 3-0ct after training with $\mathrm{MCH}(\boldsymbol{I})$. n.S., Not significant ( $p>0.05$; one-way ANOVA with Bonferroni post hoc test). ${ }^{* * *} p<0.001$ (one-way ANOVA with Bonferroni post hoc test). $n=16$ for each experiment. Bars indicate mean \pm SEM.
Figure 1. Generalization across similar odors. $\boldsymbol{A}$, Chemical structures of the three odorants used: $3-0 \mathrm{ct}, 1-0 \mathrm{ct}$, and MCH. $\boldsymbol{B}, 0 \mathrm{dor}$ preference of flies for the odorants 3-0ct, 1-0ct, and $\mathrm{MCH}$ at the dilutions indicated within the bars in a T-maze choice situation against the diluent mineral oil (Oil). White bars represent the preferences of naive flies. Gray bars represent the responses of flies that were preexposed to the respective odor for $1 \mathrm{~min}$. No significant differences between preexposed and naive animals (twosample $t$ test), and no differences between the three odors at the indicated concentrations were observed. n.s., Not significan $(p>0.05$; one-way ANOVA). Bars indicate mean $\pm \mathrm{SEM} ; n=16$ for preexposed animals, $n=8$ for naive animals. No preference for the diluent mineral oil was detected when tested against blank air. C, Schematic illustration of the absolute associative conditioning regimen. Green box represents odor or diluent (mineral oil) that is temporally paired with electric shocks 
evoked $\mathrm{Ca}^{2+}$ activity in terminal arborizations of OSNs in the antennal lobes. Here, distinct OSNs expressing defined receptor proteins converge into identified glomeruli (Couto et al., 2005; Fishilevich and Vosshall, 2005; Vosshall and Stocker, 2007). Odor representations in the antennal lobes can therefore be described as overlapping, combinatorial glomerular activity patterns (Fiala et al., 2002; Wang et al., 2003). Using two-photon microscopy, we focused on three focal planes covering 29 of 51 olfactory glomeruli (Caron et al., 2013). Glomerular subdivisions of DA4 and VM5 could not be anatomically identified based on GCaMP3.0 expression, and VA1 was subdivided into three compartments: dorsal, lateral, and medial (Figs. 2 and 3). Stimulation with 1-Oct activated a glomerulus that could not be unambiguously identified and was therefore referred to as glomerulus X (Figs. 2C,D and $3 A$ ). 1-Oct and 3-Oct both evoked strong $\mathrm{Ca}^{2+}$ activity in a largely overlapping subset of glomeruli (Figs. $2 A-D$ and $3 A$ ). On the other hand, $\mathrm{MCH}$ induced a relatively more distinct activity pattern (Figs. 2C,D and $3 A$ ). Taking the representative odor responses measured in the three focal planes into account, 1-Oct and 3-Oct evoked more similar, overlapping neuronal activity in the antennal lobe compared with those evoked by MCH (Fig. $3 A$ ). To assess the degree of similarity between odor-evoked glomerular activities more quantitatively, we reduced the multidimensionality determined by the number of identified glomeruli using a PCA to illustrate the time course of glomerular $\mathrm{Ca}^{2+}$ dynamics. Figure $3 B$ shows that the $\mathrm{Ca}^{2+}$ dynamics across all measured glomeruli evoked by 3 -Oct and 1-Oct are more similar to each other than to MCH. When we calculated the Euclidean distances across the maximum $\mathrm{Ca}^{2+}$ activity in all optically recorded glomeruli, we found a significantly smaller distance between 3-Oct and 1-Oct to each other than between either of these and $\mathrm{MCH}\left(\mathrm{MCH} / 3\right.$-Oct vs $\mathrm{MCH} / 1$-Oct: $t_{(10)}=1.1, p=0.85$; $\mathrm{MCH} / 3$-Oct vs 1-Oct/3-Oct: $t_{(10)}=5.3, p<0.01 ; \mathrm{MCH} / 1$-Oct vs 1-Oct/3-Oct: $t_{(10)}=4.2, p<0.01$; one-way repeated-measures ANOVA with Bonferroni post hoc test) (Fig. 3C). We additionally assessed the degree of similarity by calculating the Pearson's correlation between the $\mathrm{Ca}^{2+}$-activity patterns evoked by the three odorants at the time point of maximal $\mathrm{Ca}^{2+}$ amplitude. The correlation between the similar odors is significantly larger compared with the correlation between the dissimilar odor pairs $\left(\mathrm{MCH} / 3\right.$-Oct vs $\mathrm{MCH} / 1$-Oct: $t_{(10)}=1.6, p=0.45 ; \mathrm{MCH} / 3-\mathrm{Oct}$ vs 1 -Oct $/ 3$-Oct: $t_{(10)}=3.9, p<0.01 ; \mathrm{MCH} / 1$-Oct vs 1 -Oct $/ 3$-Oct: $t_{(10)}=5.4, p=<0.01$; one-way repeated-measures ANOVA with Bonferroni post hoc test) (Fig. 3D). In conclusion, our experiments revealed that the similarity between the odors as observed in the animals' behavior is also reflected in the odor representation in OSNs within the antennal lobe.

OSNs synapse onto second-order olfactory projection neurons (OPNs) within the glomeruli of the antennal lobe. Because odor-evoked glomerular activity patterns are subject to processing by interneurons horizontally interconnecting the glomeruli, we asked whether the similarity between neuronal odor representations detected in OSNs is maintained at the level of OPNs. Therefore, we monitored odor-evoked $\mathrm{Ca}^{2+}$ activity in the arborizations of OPNs in the antennal lobes in three focal planes (Fig. 4A-C) that, together, captured glomeruli that partially overlapped with those analyzed in OSNs. Together, we recorded odor-evoked $\mathrm{Ca}^{2+}$ responses in OPNs within 18 identifiable glomeruli (Figs. $4 A-D$ and $5 A$ ), of which 12 were also monitored at the level of OSNs (Figs. $2 A-C$ and $3 A$ ). Compared with odorevoked $\mathrm{Ca}^{2+}$ transients in OSNs (Fig. $2 D$ ), those observed in OPNs are more variable in their dynamic structure (Fig. $4 D$ ), and activities of identified glomeruli (e.g., glomeruli DA2 or DM1) differ between the two neuronal populations (Figs. $3 A$ and $5 A$ ). However, when analyzing odor-induced $\mathrm{Ca}^{2+}$ activity patterns across all 18 glomeruli in OPNs, the two similar odors 3-Oct and 1-Oct are, again, more similar to each other in terms of neuronal representation than to the dissimilar odor $\mathrm{MCH}$ (Fig. 5A). In a PCA, the spatiotemporal activity of the dissimilar odor separates clearly from the similar ones (Fig. 5B). Just as it is the case in OSNs (Fig. 3C), we observed a significantly smaller distance between $\mathrm{Ca}^{2+}$ activity evoked by 3-Oct and 1-Oct than between either of these and $\mathrm{MCH}$ when the maximal Euclidean distances across all optically recorded glomeruli during odor stimulation was calculated (MCH/3-Oct vs MCH/1-Oct: $t_{(58)}=4.3, p<0.01$; $\mathrm{MCH} / 3$-Oct vs 1-Oct/3-Oct: $t_{(58)}=12.2, p<0.01 ; \mathrm{MCH} / 1$-Oct vs 1 -Oct $/ 3$-Oct: $t_{(58)}=7.9, p<0.01$; one-way repeated-measures ANOVA with Bonferroni post hoc test) (Fig. 5C). In accordance, a significantly higher Pearson's correlation coefficient was found between $\mathrm{Ca}^{2+}$ patterns evoked by 3-Oct and 1-Oct than between either of these and signals evoked by $\mathrm{MCH}(\mathrm{MCH} / 3-\mathrm{Oct}$ vs $\mathrm{MCH} / 1$-Oct: $t_{(58)}=3.9, p<0.01 ; \mathrm{MCH} / 3$-Oct vs 1 -Oct/3-Oct: $t_{(58)}=3.7, p<0.01 ; \mathrm{MCH} / 1$-Oct vs 1 -Oct/3-Oct: $t_{(58)}=7.6, p<$ 0.01; one-way repeated-measures ANOVA with Bonferroni post hoc test) (Fig. 5D). Conclusively, the similarity between the odors as observed in the animals' behavior is also reflected in the odor representation in second-order olfactory neurons.

\section{Local interneurons in the antennal lobe are required for discrimination between two similar odors}

The degree of generalization between stimuli is typically inversely related to their discriminability. However, generalization as an effect of transferring a learned response to a novel, similar stimulus requires that the two stimuli are discernable by an animal. Therefore, we asked whether the two similar odors could be discriminated by the animals at all. Indeed, they could, as the following experiment demonstrates. In a differential training procedure as illustrated in Figure 6A, either 3-Oct or 1-Oct was paired with electric shocks $\left(\mathrm{CS}^{+}\right)$, and the other, similar odor was explicitly presented without punishment $\left(\mathrm{CS}^{-}\right)$. In a subsequent choice situation with both odors as alternatives, the animals clearly avoided the $\mathrm{CS}^{+}$(Fig. 6B). Omission of the electric shocks resulted in indifferent behavior (Fig. $6 B$ ). Interestingly, the response was asymmetric for the two odors after conditioning. Training with 1-Oct as a $\mathrm{CS}^{+}$and 3-Oct as a $\mathrm{CS}^{-}$caused a strong aversion of the $\mathrm{CS}^{+}$in a subsequent choice situation between both odorants. The converse experiment, with 3-Oct as the $\mathrm{CS}^{+}$and 1-Oct as the $\mathrm{CS}^{-}$, resulted in a much weaker avoidance of the $\mathrm{CS}^{+}$(untrained vs 3-Oct punished: $t_{(30)}=3.6, p<$ 0.01 ; 1 -Oct punished vs 3-Oct punished: $t_{(30)}=13.8, p=<$ 0.01 ; 1 -Oct punished vs untrained: $t_{(30)}=10.2, p=<0.01$; one-way ANOVA with Bonferroni post hoc test) (Fig. 6B, top). This demonstrates that an equal learnability of the two odors in an absolute training regimen does not imply equal discrimination learning in a differential conditioning paradigm. To correct for these odor-specific effects, we combined preference indices of two reciprocal experiments to a learning index (Fig. 6B, bottom graph). Clearly, 1-Oct and 3-Oct could be differentiated by the animals. However, compared with differential training of dissimilar odors, either 1-Oct versus $\mathrm{MCH}$ or 3-Oct versus $\mathrm{MCH}$, the learning index was significantly lower in magnitude, which confirmed the relatively lower discriminability of the two similar odors (3-Oct/1-Oct vs $\mathrm{MCH} / 3$ Oct: $t_{(30)}=3.2, p<0.01 ; 3$-Oct/1-Oct vs $\mathrm{MCH} / 1$-Oct: $t_{(30)}=$ $3.2, p<0.01 ; \mathrm{MCH} / 1$-Oct vs MCH/3-Oct: $t_{(30)}=0.05, p=1$; one-way ANOVA with Bonferroni post hoc test). 
A

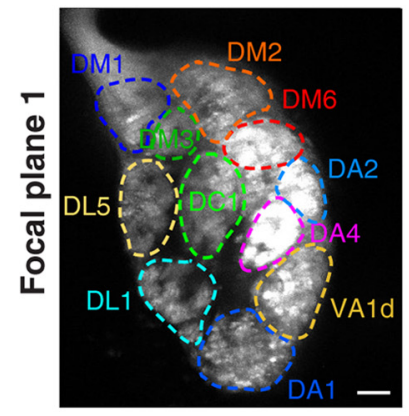

B

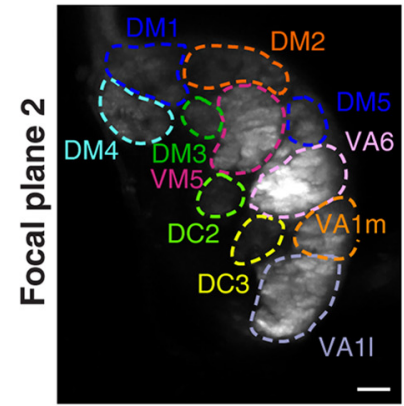

C

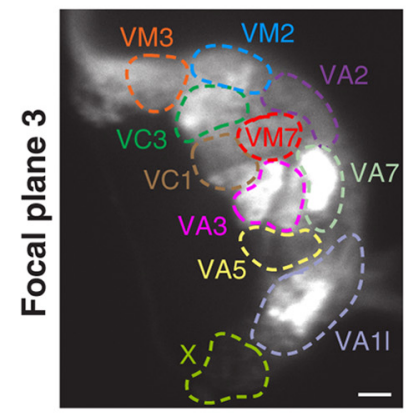

D
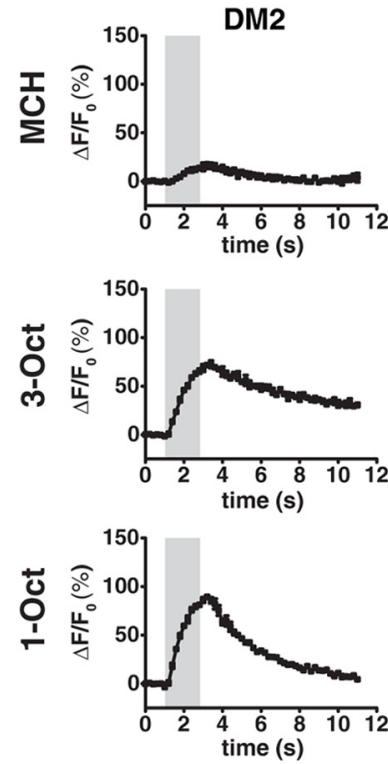
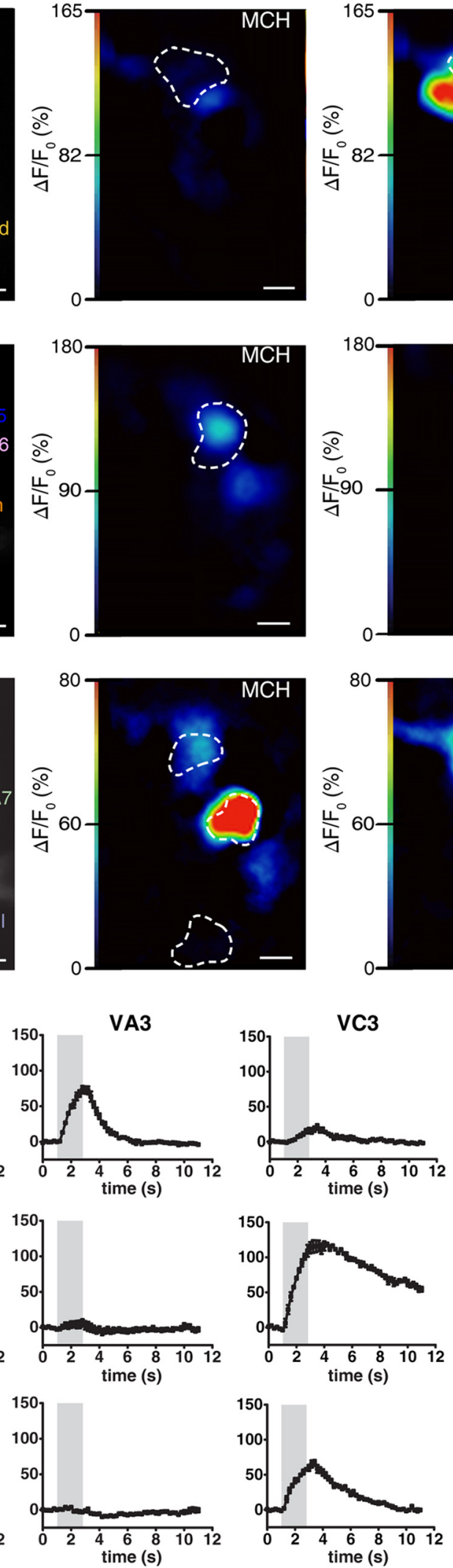
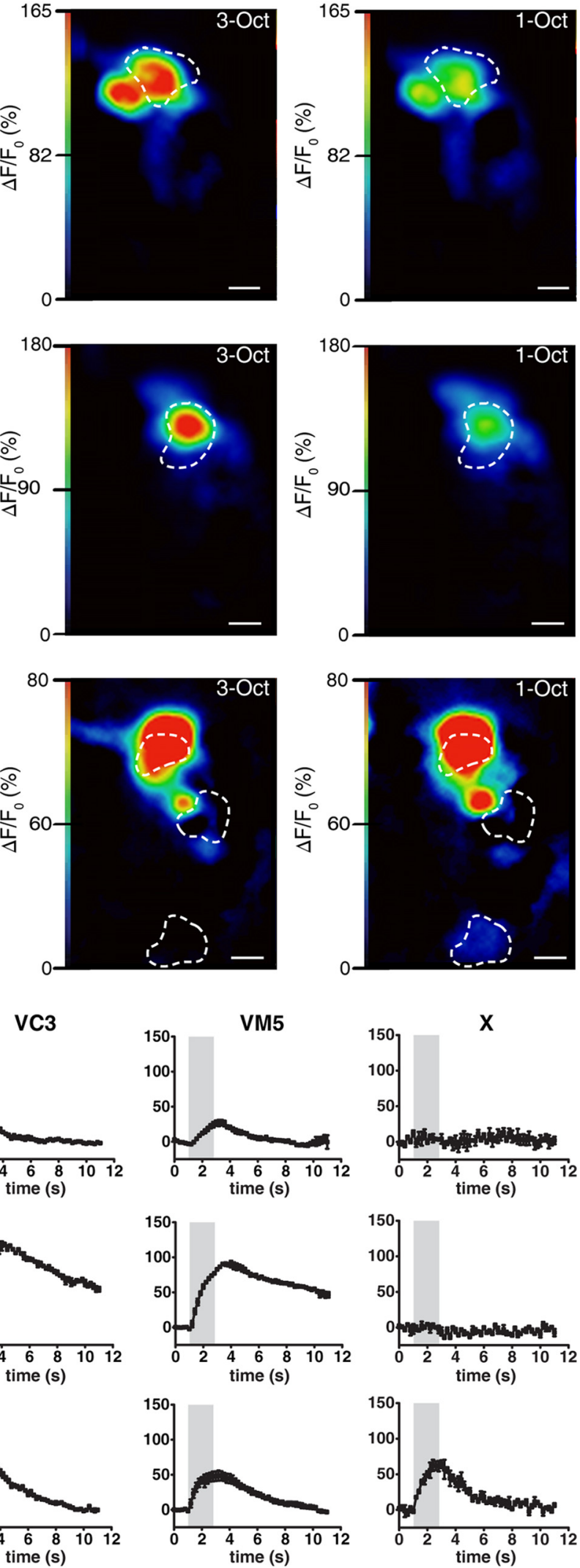

Figure 2. Two-photon $\mathrm{Ca}^{2+}$ imaging in olfactory sensory neurons in the antennal lobe reveals overlapping glomerular activity pattems evoked by similar odorants. $\mathrm{A}-\mathrm{C}$, Expression of the $\mathrm{Ca}^{2+}$ sensor $\mathrm{GCaMP3.0} \mathrm{in}$ olfactory sensory neurons visualized in three focal planes $(\boldsymbol{A}-\boldsymbol{C})$ using two-photon microscopy shown for one representative animal. The outlines of identified olfactory glomeruli are indicated as dashed, colored lines. ${ }^{2+}{ }^{2+}$ increase as relative change in fluorescence $\left(\Delta \mathrm{F} / \mathrm{F}_{0}\right)$ evoked by the odorants $\mathrm{MCH}, 3-0 \mathrm{ct}$, and 1-0ctis indicated as false colors. Scalebars, $10 \mu \mathrm{m}$. D, Time courses of $\mathrm{Ca}^{2+}$ changes in the antennal lobe of the fly shown in $A-C$ in the glomeruli DM2, VA3, VC3, VM5, and Xevoked by the odors $\mathrm{MCH}, 3-0 \mathrm{ct}$, and 1-0ct. The gray bars represent the time window of odor presentation. Graphs representmean \pm SEM of $\Delta \mathrm{F} / \mathrm{F}_{0}$ values across threestimulations. 
A

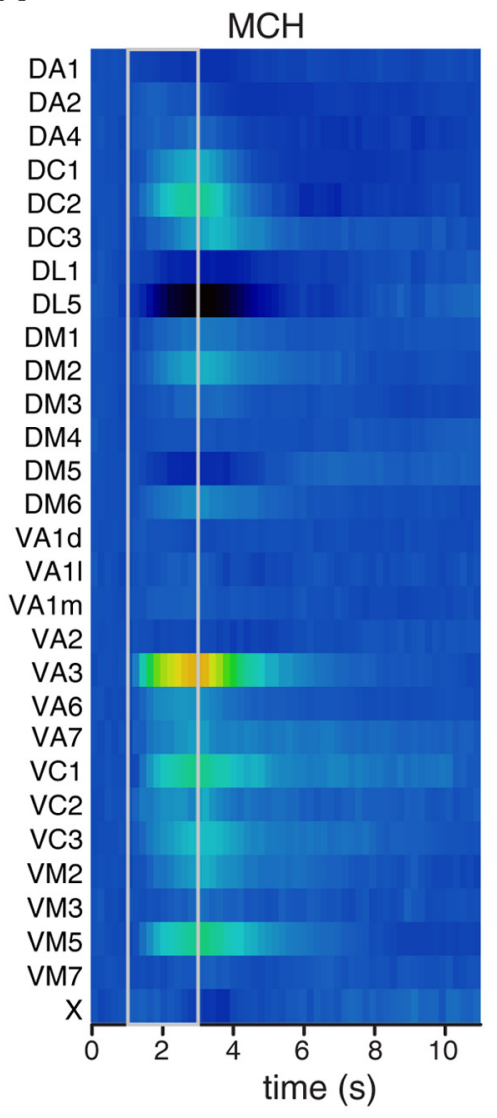

B

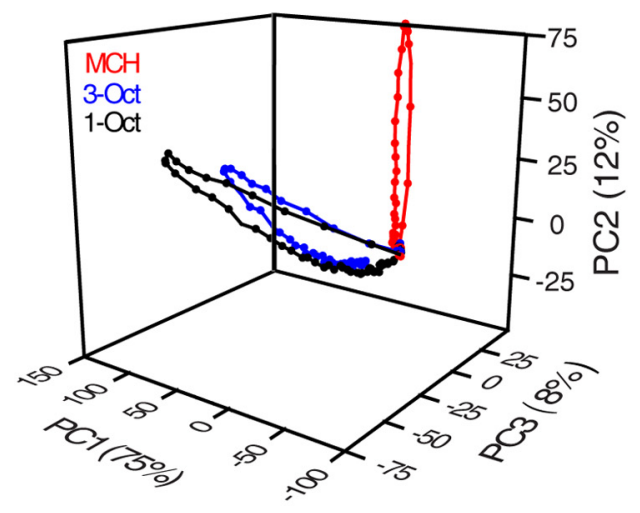

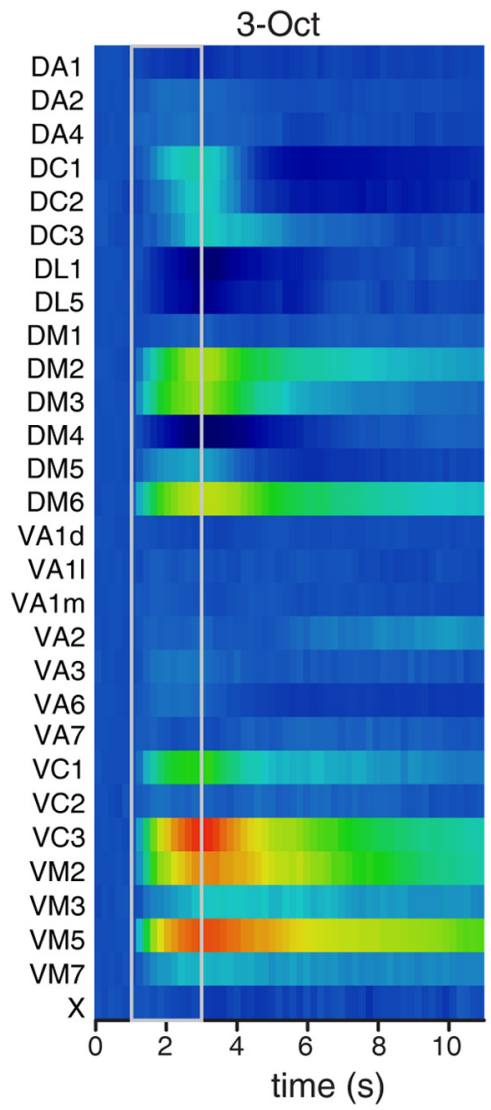

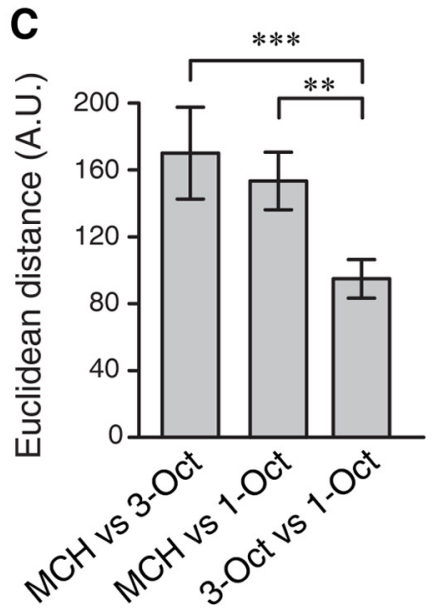

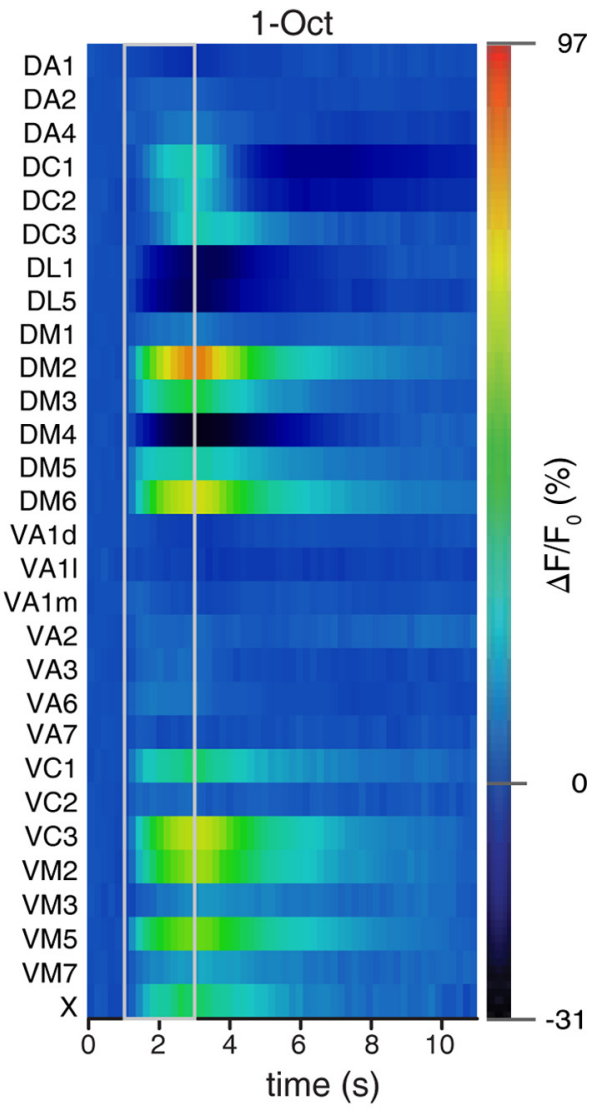

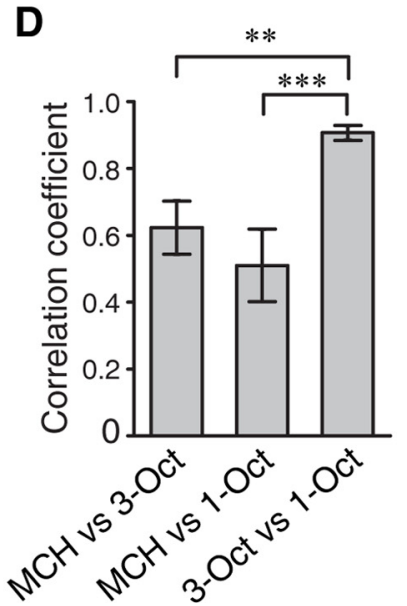

Figure 3. Dynamics and similarity of glomerular activity patterns in sensory neurons in the antennal lobe. $\boldsymbol{A}, 0$ dor-evoked changes in fluorescence emitted by the $\mathrm{Ca}^{2+}$ sensor protein $\mathrm{GCaMP3} .0$ over time, shown as false colors in 29 identified glomeruli, in response to the odorants MCH, 3-0ct, and 1- 0 ct. Gray lines indicate odor onset and offset. Values indicate mean; $n=6$ animals. $B$, PCA of the time courses of the mean odor-evoked responses in olfactory sensory neurons across all 29 glomeruli. The first three principal components covered $>95 \%$ of the variance. $C$, Euclidean distances between the spatially distributed $\mathrm{Ca}^{2+}$ activity evoked by the three odorants at the time point of maximal $\mathrm{Ca}^{2+}$ change at odor offset. The Euclidean distance between the similar odors is significantly smaller than between dissimilar odors. D, Pearson's correlation between spatially distributed glomerular $\mathrm{Ca}^{2+}$ activity patterns evoked by the three odorants at the time point of maximal $\mathrm{Ca}^{2+}$ change (i.e., maximal correlation). The correlation coefficient is significantly higher between the similar odors than between the dissimilar odors. ${ }^{* * *} p<0.001$ (repeated measures one-way ANOVA with Bonferroni post hoc test). ${ }^{* *} p<0.01$ (repeated measures one-way ANOVA with Bonferroni post hoc test). $n=6$. Bars indicate mean \pm SEM.

We reasoned that the highly overlapping odor representation at the level of OSNs and OPNs for 1-Oct and 3-Oct compared with $\mathrm{MCH}$ might provide a physiological cause for their higher perceptual similarity. It has been suggested that inhibitory local interneurons in the antennal lobe contribute to a decorrelation of odor representations and, as a consequence, to fine discrimination of similar odors (Stopfer et al., 1997; Sachse and Galizia, 2002; Wilson and Laurent, 2005). To test whether local interneu- rons are indeed part of the neuronal circuitry contributing to olfactory acuity, we used temperature-sensitive shibire expression (Kitamoto, 2001) to selectively block synaptic transmission from subpopulations of inhibitory local interneurons during training and test. We focused on two groups of inhibitory local interneurons that had been described in detail previously (Chou et al., 2010; Seki et al., 2010): type I (LN1) and type II (LN2) interneurons, which are targeted by the two Gal4 enhancer trap lines, NP 
A

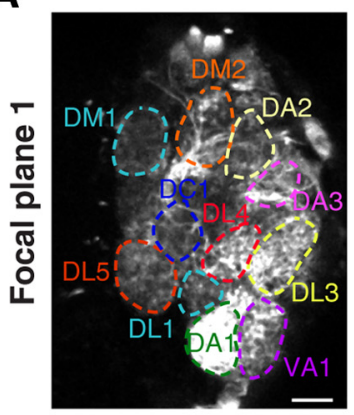

B

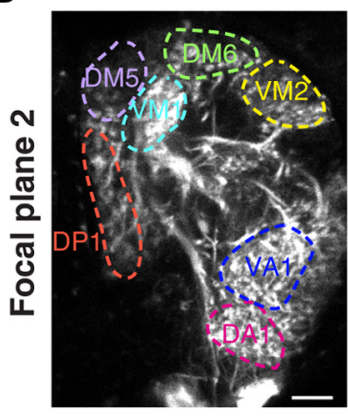

C

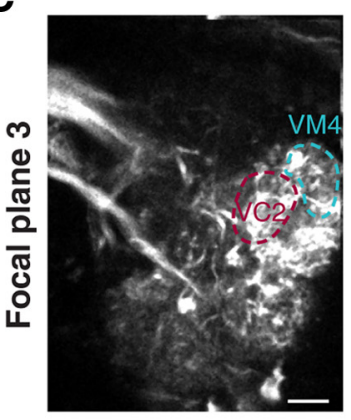

D
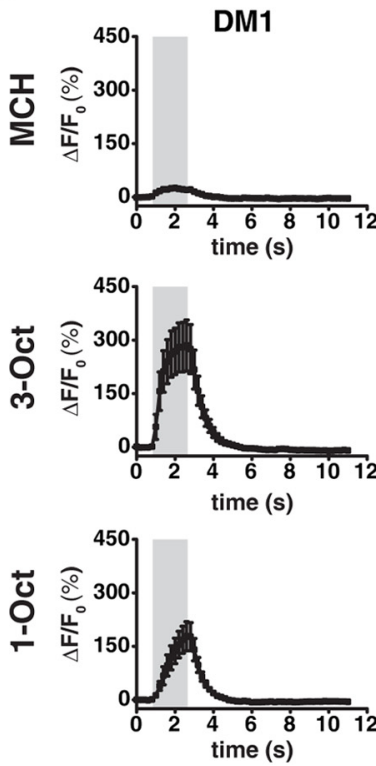
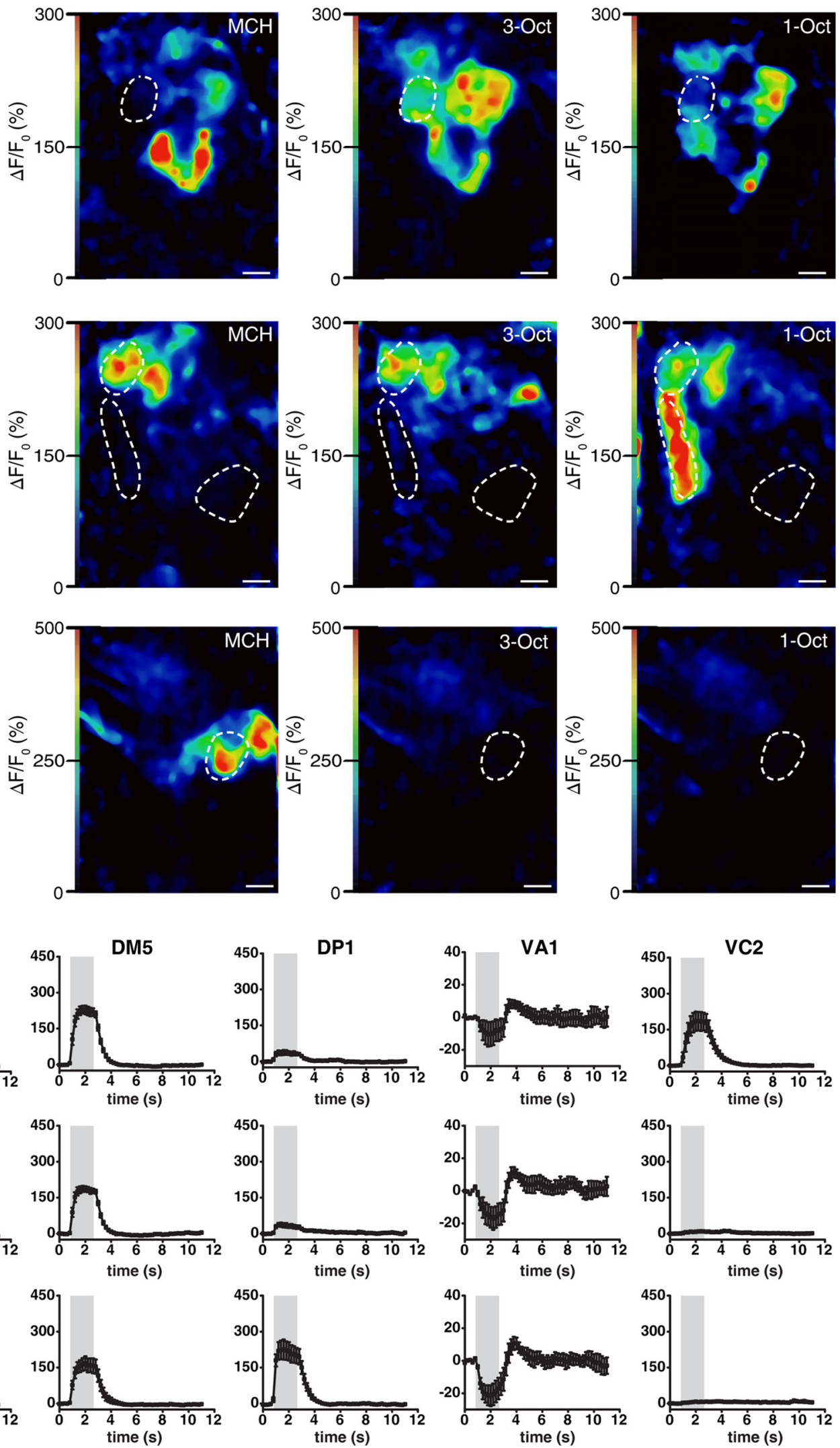

Figure 4. Two-photon $\mathrm{Ca}^{2+}$ imaging in olfactory projection neurons at the level of the antennal lobe. $A-C$, Expression of the $\mathrm{Ca}^{2+}{ }^{2+}$ sensor GCaMP3.0 in olfactory projection neurons visualized in threefocal planes (A-C using two-photon microscopy for onerepresentative animal. Theoutlines ofidentified olfactory glomeruliareindicatedas dashed, colored lines. $\mathrm{Ca}^{2+}$ increaseas relativechangeinfluorescence $\left(\Delta \mathrm{F} / \mathbb{F}_{0}\right)$ evoked bytheodorants MCH,3-0ct, and 1-0ctisindicated asfalse colors. Scalebars, $10 \mu \mathrm{m}$. D, Time courses of mean $\mathrm{Ca}^{2+}$ changes in the antennall lobein the glomeruli DM1, DM5,DP1, VA1, and VC2 evoked by the odors MCH, 3-0ct, and 1-0ct. Gray bars represent the time window of odor presentation. Graphs represent mean $\pm \mathrm{SEM}$. of $\Delta \mathrm{F} / \mathrm{F}_{0}$ values ( $n=20$ animals). 
A

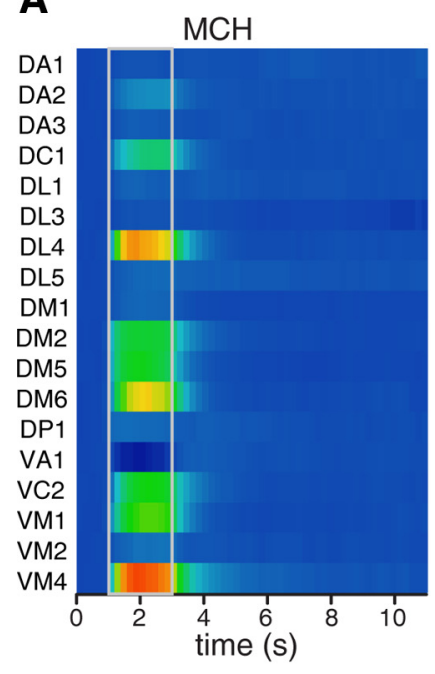

B

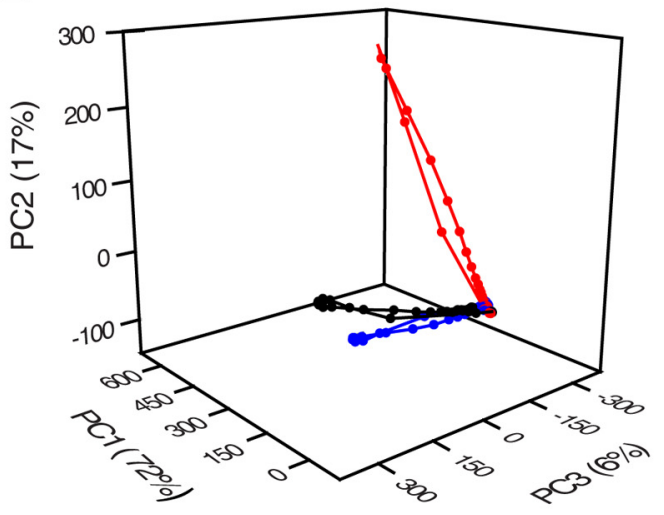

3-Oct

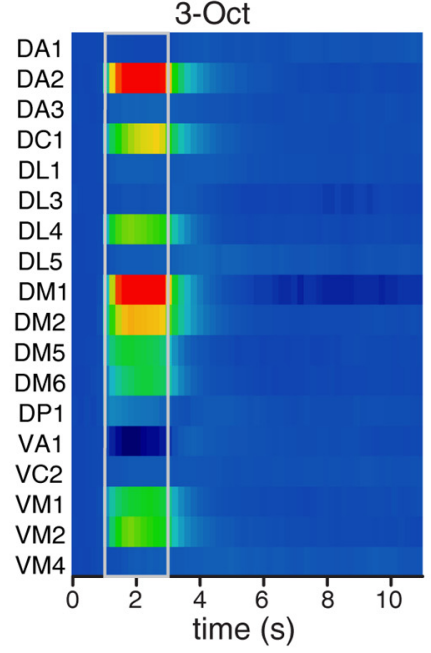

C

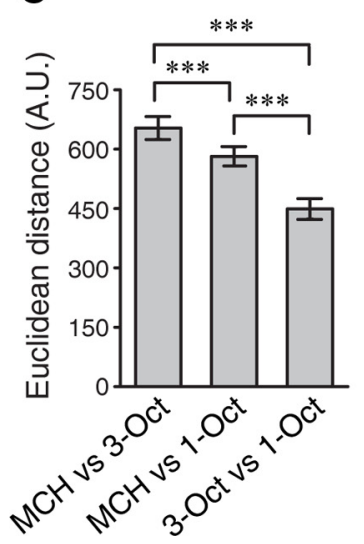

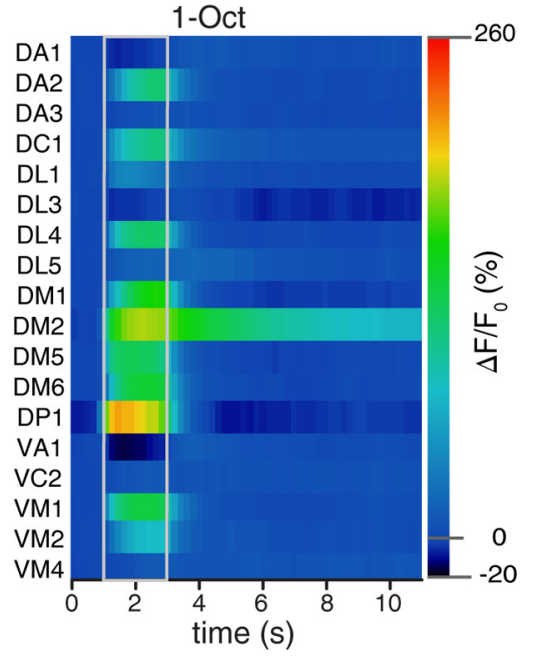

D

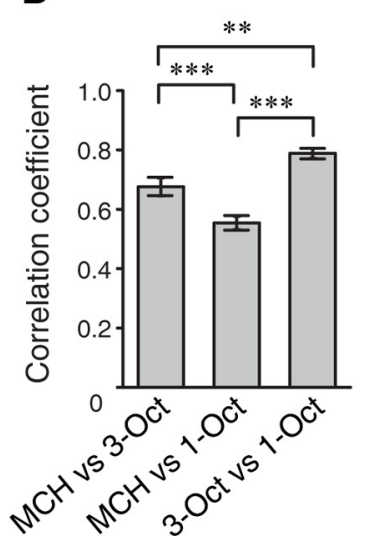

Figure 5. Dynamics and similarity of glomerular activity patterns in olfactory projection neurons in the antennal lobe. $A, 0$ dor-evoked changes in fluorescence emitted by the $\mathrm{Ca}^{2+}$ sensor protein GCaMP3.0 over time, shown as false colors in 18 identified glomeruli, in response to the odorants $\mathrm{MCH}, 3-0 \mathrm{ct}$, and 1-0ct. Odor onset and offset are indicated by gray lines. Values indicate mean; $n=$ 20 animals. $\boldsymbol{B}$, PCA of the time courses of the mean odor-evoked responses in olfactory projection neurons across all $18 \mathrm{glomeruli}$. The first three principal components covered $95 \%$ of the variance. $C$, Euclidean distances between the spatially distributed $\mathrm{Ca}^{2+}$ activity evoked by the three odorants at the time point of maximal $\mathrm{Ca}^{2+}$ change, which was variable across individuals. The Euclidean distance between the similar odors was significantly smaller than between dissimilar odors. $\boldsymbol{D}$, Pearson's correlation between spatially distributed glomerular $\mathrm{Ca}^{2+}$ activity patterns evoked by the three odorants at the time point of maximal correlation. The correlation coefficient was significantly higher between the similar odors than between the dissimilar odors. ${ }^{* * *} p<0.001$ (repeated measures one-way ANOVA with Bonferroni post hoc test). ${ }^{* *} p<0.01$ (repeated measures one-way ANOVA with Bonferroni post hoc test). $n=20$. Bars indicate mean \pm SEM.

1227-Gal4 and NP 2426, respectively (Sachse et al., 2007). Type II interneurons could not be tested in learning assays because the respective Gal4 line (NP 2426) expresses Gal4 also in a large number of neurons located in the thoracic ganglia in a position similar to motor neurons (Fig. 6C), and flies of this Gal4 strain show locomotion deficits after expression of shibire ${ }^{t s}$ and at the restrictive temperature (Table 1). Type I local interneurons, however, could be tested, as we found the respective Gal4 line (NP 1227) to be specific for an expression in these neurons (Fig. 6D), and expression of shibire ${ }^{t s}$ did not alter locomotion, odor preferences, or electric shock avoidance at permissive or restrictive temperatures (Table 2). Of course, we cannot completely exclude Gal4 expression in neurons other than local interneurons that might be below our detection threshold. The temperaturedependent block of synaptic output from these neurons during both differential conditioning and the test situation significantly impaired discrimination between the two similar odors. Whereas at the permissive temperature of $25^{\circ} \mathrm{C}$ no significant difference between the three genotypes tested was observed $\left(F_{(2,25)}=3.13\right.$, $p=0.06$; one-way ANOVA), at the restrictive temperature of $32^{\circ} \mathrm{C}$ the learning index was significantly reduced in flies expressing shibire ${ }^{t s}$ in LN1-type interneurons (LN1 $>$ Shi $^{\text {ts }}$ vs LN1-Gal4: $t_{(24)}=3.1, p<0.05$; UAS:Shi ${ }^{\text {ts }}$ vs LN1 $>$ Shi $^{\text {ts }}: t_{(24)}=-3.5, p<$ 0.01; UAS:Shi ${ }^{\text {ts }}$ vs LN1-Gal4: $t_{(24)}=-0.5, p=1$; one-way ANOVA with Bonferroni post hoc test) (Fig. 6E). In contrast, performance after differential training of dissimilar odors (Fig. $6 F, G)$ was not affected by blocking synaptic transmission from type I local interneurons, independent of whether 1-Oct was trained against $\mathrm{MCH}\left(25^{\circ} \mathrm{C}: F_{(2,21)}=1, p=0.40 ; 32^{\circ} \mathrm{C}: F_{(2,21)}=\right.$ $0.1, p=0.92$; one-way ANOVA) (Fig. $6 F$ ) or 3-Oct was trained against $\mathrm{MCH}\left(25^{\circ} \mathrm{C}: F_{(2,21)}=0.7, p=0.49 ; 32^{\circ} \mathrm{C}: F_{(2,21)}=0.8\right.$, $p=0.46$; one-way ANOVA) (Fig. 6G). In addition, absolute training with only one odor, causing avoidance of this odor (Fig. $7 A, B$ ) and generalization across a similar odor (Fig. $7 C, D$ ), was not dependent on type I inhibitory local interneurons either at the permissive or at the restrictive temperature (Fig. $7 A ; 25^{\circ} \mathrm{C}$ : $F_{(2,24)}=0.8, p=0.46 ; 32^{\circ} \mathrm{C}: F_{(2,33)}=3.6, p=0.04$, post hoc pairwise comparison did not reveal any significance; Figure $7 B$; $25^{\circ} \mathrm{C}: F_{(2,23)}=0.8, p=0.47 ; 32^{\circ} \mathrm{C}: F_{(2,27)}=1.6, p=0.22$; Figure $7 C, 25^{\circ} \mathrm{C}: F_{(2,21)}=2.3, p=0.13 ; 32^{\circ} \mathrm{C}: F_{(2,21)}=0.5, p=0.63$; 
A

Training

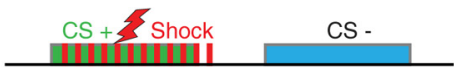

B
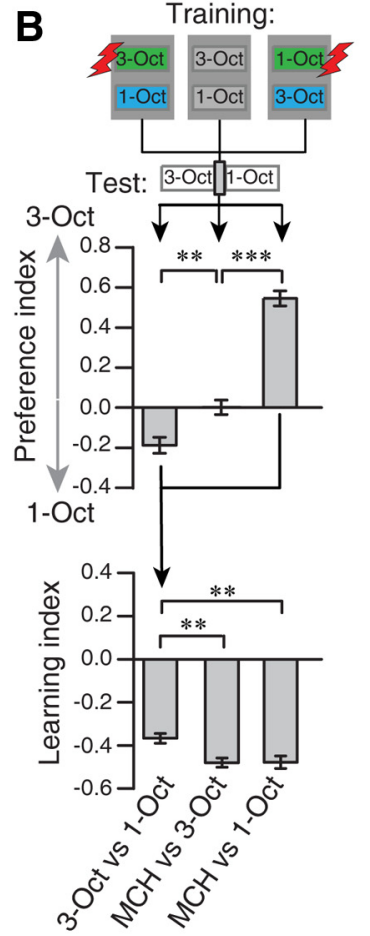

E

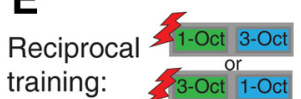

Test:
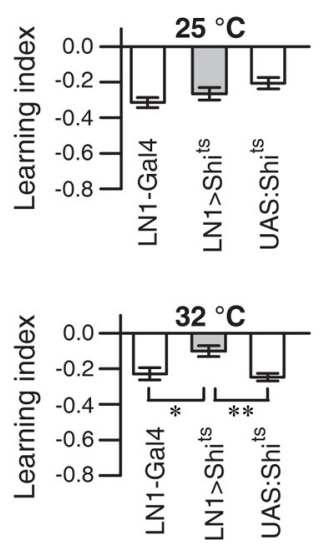

C
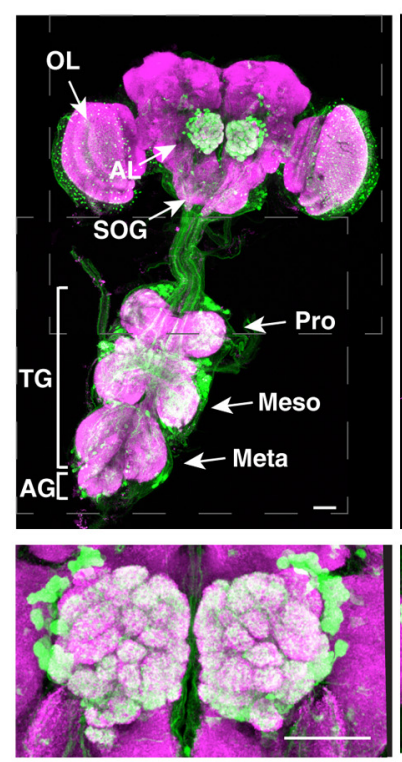

$\mathbf{F}$

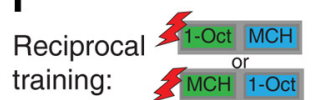

Test: $\quad 1-\mathrm{OCt}] \mathrm{MCH}$
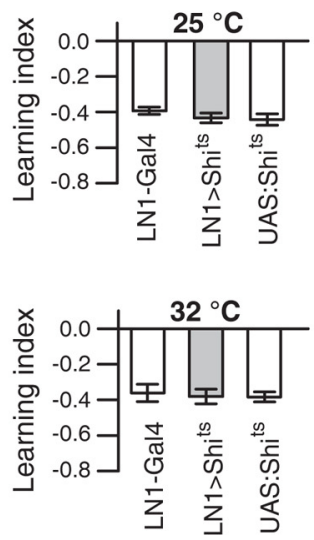

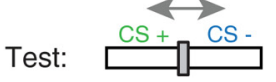

Choice situation

D
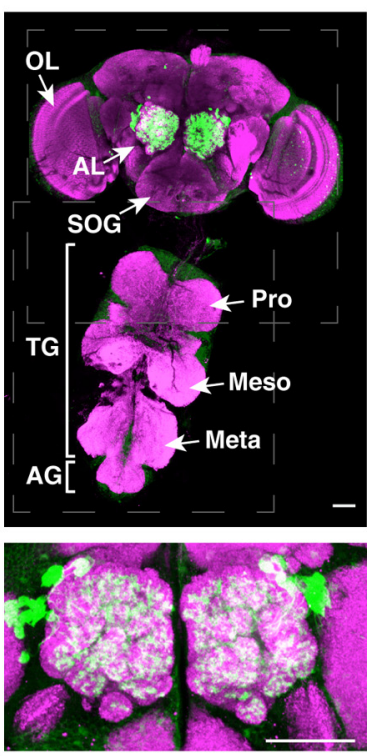

G
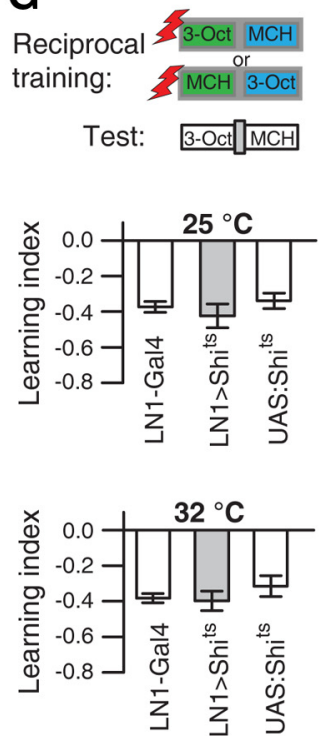

Figure 6. Local interneurons of the antennal lobes are required for fine discrimination of similar odors. A, Schematic illustration of the differential conditioning regimen. The green box represents the odor that is, as conditioned stimulus (CS ${ }^{+}$), temporally paired with electric shocks (red boxes). The blue box represents the odor presented without punishment (CS ${ }^{-}$). During the test, the trained flies are subjected to a choice situation between $\mathrm{CS}^{+}$and $\mathrm{CS}^{-}$. B, Differential training of either 3-0ct or 1-0ct resulted in avoidance of the odor temporally paired with the electric shock (as indicated as green boxes in the schematic illustration) in a choice situation for both odorants (test) (top). ${ }^{* * *} p<0.001$ (one-way ANOVA with Bonferroni post hoc test). ${ }^{*} p<0.05$ (one-way ANOVA with Bonferroni post hoc test). $n=8-13$ for each experiment. Bars indicate mean \pm SEM. When both odorants were presented without electric shocks, the response was indifferent. When the preference indices of the reciprocal training situations were combined (bottom), the resulting learning index was significantly lower compared with training with either 1-0ct or 3-0ct against the dissimilar odorant MCH (bottom). ${ }^{* *} p<0.01$ (one-way ANOVA with Bonferroni post hoc test). $n=8-13$ for each experiment. Bars indicate mean \pm SEM. C, GFP expression in the central brain and the thoracic ganglia under control of NP2426Gal4 (LN2-Gal4). D, GFP expression in the central brain and the thoracic ganglia under control of NP1227-Gal4 (LN1-Gal4). The expression is confined to local interneurons in the antennal lobe, as indicated in the magnified image. $C, \boldsymbol{D}$, Green represents anti-GFP immune reactivity; magenta represents anti-nc82 immune reactivity. Scale bars, $50 \mu \mathrm{m}$. AL, Antennal lobe; $0 \mathrm{~L}$, optic

Figure $7 D ; 25^{\circ} \mathrm{C}: F_{(2,22)}=0.1, p=0.90$; $32^{\circ} \mathrm{C}: F_{(2,21)}=0.1, p=0.95$; one-way ANOVA). These results demonstrate a role of inhibitory local interneurons for behaviorally expressed fine discrimination of similar odors in Drosophila. Moreover, chemical synaptic transmission from these neurons is dispensable for the discrimination of dissimilar odors and for odor generalization.

\section{Differential training causes enhanced olfactory acuity due to conditioned} excitation and conditioned inhibition The experiments reported so far show that flies generalize across chemically similar odors after absolute training, but they can discriminate between them after differential training. We asked next whether it is indeed the differential training procedure that enhances fine discrimination as observed in choice behavior. We therefore subjected flies to a choice test between 1-Oct and 3-Oct after either differential or absolute training (Fig. 8A). In differential training, one odor was presented as $\mathrm{CS}^{+}$, and the other as $\mathrm{CS}^{-}$, whereas in absolute training the $\mathrm{CS}^{-}$was replaced by the presentation of the diluent only. We found that avoidance of the $\mathrm{CS}^{+}$was much more pronounced after differential training than after absolute training (1-Oct absolute vs differential training: $t_{(30)}=-4.0$, $p<0.01$; 3-Oct absolute vs differential training: $t_{(30)}=-3.4, p<0.01$; twosample $t$ test) (Fig. 8A). This demonstrates that a differential training procedure can cause an enhancement in olfactory acuity. Again, we found asymmetric learning in the choice situation: learned responses were higher in the case of 1-Oct as $\mathrm{CS}^{+}$ compared with 3-Oct as $\mathrm{CS}^{+}$(Fig. 8A). The two training regimens, absolute and differential training, differed only in the

$\leftarrow$

lobe; $\mathrm{SOG}$, suboesophageal ganglion; $\mathrm{TG}$, thoracic ganglia; $\mathrm{AG}$, abdominal ganglia; Pro, prothoracic ganglion; Meso, mesothoracic ganglion; Meta, metathoracic ganglion. $\boldsymbol{E}$, Differential, reciprocal training of 1-0ct and 3-0ct in flies expressing shibirets under control of LN1-Gal4 and the respective genetic controls. Training and test at the permissive temperature of $25^{\circ} \mathrm{C}$ did not result in different learning indices for all three genotypes. Significantly decreased learning was observed in flies expressing shibire ${ }^{t s}$ in local interneurons at the restrictive temperature of $32^{\circ} \mathrm{C} .{ }^{* *} p<0.01$ (one-way ANOVA with Bonferroni post hoc test). ${ }^{*} p<0.05$ (one-way ANOVA with Bonferroni post hoc test). $n=8-13$ for each experiment. Bars indicate mean \pm SEM. $F, G$, Differential, reciprocal training of the dissimilar odorants $1-0 c t$ against $\mathrm{MCH}(\boldsymbol{F})$ or 3-0ct against MCH $(\boldsymbol{G})$ was not significantly $(p>0.05)$ affected by a temperature-dependent block of local interneurons. One-way ANOVA with Bonferroni post hoc test. $n=8-13$ for each experiment. Bars indicate mean \pm SEM. 
Table 1. Blocking synaptic transmission in neurons targeted by NP2426-Gal4 results in locomotion deficits ${ }^{a}$

\begin{tabular}{lllll}
\hline Experiment & Temperature, $^{\circ} \mathrm{C}$ & LN2-Gal4 & LN2 $>$ Shi & UAS:Shi \\
\hline Climbing index & 25 & $0.77 \pm 0.02$ & $0.85 \pm 0.02$ & $0.68 \pm 0.03$ \\
& 32 & $0.60 \pm 0.03$ & $0.40 \pm 0.05$ & $0.73 \pm 0.05$ \\
\hline
\end{tabular}

${ }^{a}$ At the restrictive temperature, expression of shibirets under control of NP2426-Gal4 led to a decreased climbing index compared with the genetic controls, Values indicate mean \pm SEM; $n=5$ for each experiment.

Table 2. Blocking synaptic transmission in neurons targeted by NP1227-Gal4 does not alter locomotion, shock avoidance, or odor preference ${ }^{a}$

\begin{tabular}{llrrr}
\hline Experiment & Temperature, ${ }^{\circ} \mathrm{C}$ & \multicolumn{1}{l}{ LN1-Gal4 } & \multicolumn{1}{l}{ LN1 $>$ Shi } & \multicolumn{1}{l}{ UAS:Shi } \\
\hline Climbing index & 25 & $0.71 \pm 0.01$ & $0.71 \pm 0.04$ & $0.72 \pm 0.02$ \\
& 32 & $0.73 \pm 0.06$ & $0.71 \pm 0.04$ & $0.73 \pm 0.03$ \\
Shock avoidance & 25 & $-0.64 \pm 0.03$ & $-0.73 \pm 0.05$ & $-0.65 \pm 0.04$ \\
& 32 & $-0.63 \pm 0.08$ & $-0.57 \pm 0.10$ & $-0.45 \pm 0.10$ \\
3-0ct preference & 25 & $0.31 \pm 0.04$ & $0.38 \pm 0.09$ & $0.30 \pm 0.06$ \\
& 32 & $0.32 \pm 0.05$ & $0.38 \pm 0.05$ & $0.30 \pm 0.06$ \\
1-0ct preference & 25 & $0.49 \pm 0.05$ & $0.44 \pm 0.06$ & $0.32 \pm 0.06$ \\
& 32 & $0.26 \pm 0.03$ & $0.28 \pm 0.06$ & $0.21 \pm 0.06$
\end{tabular}

${ }^{a}$ Comparable climbing indices were observed in flies expressing shibire ${ }^{\text {ts }}$ under control of NP1227-Gal4 at the permissive and the restrictive temperature. $n=5$ for each experiment. The shock avoidance index of flies expressing shibire ${ }^{\text {ts }}$ in LN1 neurons was comparable with the genetic controls at the permissive and the restrictive temperature. The behavior towards 1-octen-3-ol and 3-octanol in a T-maze choice test with the diluent was not significantly different in flies expressing shibirets under control of NP1227-Gal4 at both temperatures tested. Values indicate mean $\pm \mathrm{SEM} ; n=8$ for each experiment.

presentation of the $\mathrm{CS}^{-}$, and the temporal order of $\mathrm{CS}^{+}$and $\mathrm{CS}^{-}$ presentation was balanced in each experiment. We wondered whether the timing of the $\mathrm{CS}^{-}$might affect the learned discrimination. This is of importance as the enhanced discriminability of the two odors might have resulted from potential backward conditioning caused by the $\mathrm{CS}^{-}$after the $\mathrm{CS}^{+} /$unconditioned stimulus (US) stimulation. Indeed, inhibitory learning through backward US-CS paring has been described in Drosophila and honeybees (Hellstern et al., 1998; Tanimoto et al., 2004). However, when preference indices of the two groups of animals were separated post hoc, we did not find any significant difference between those animals that had perceived the $\mathrm{CS}^{+}$first and the $\mathrm{CS}^{-}$ afterward and those animals that had received $\mathrm{CS}^{+}$and $\mathrm{CS}^{-}$in the reverse order (1-Oct differential training $\mathrm{CS}^{+}$vs CS $^{-}: t_{(14)}=$ $1.1, p=0.3$; 1-Oct absolute training $\mathrm{CS}^{+}$vs $\mathrm{CS}^{-}: t_{(14)}=-1.6$, $p=0.13$; 3-Oct absolute training $\mathrm{CS}^{+}$vs $\mathrm{CS}^{-}: t_{(14)}=-1.6, p=$ 0.13 ; 3-Oct differential training $\mathrm{CS}^{+}$vs $\mathrm{CS}^{-}: t_{(14)}=-0.9, p=$ 0.38 ; two-sample $t$ test) (Fig. $8 B$ ). The contribution of the $\mathrm{CS}^{-}$to enhanced olfactory acuity is therefore not equivalent to a US-CS backward pairing. However, its effect could not be attributed to a mere adaptation to the odorant used as $\mathrm{CS}^{-}$either, because exposure of the flies to either odor for $1 \mathrm{~min}$ did not alter their subsequent behavior toward the odor $(\mathrm{MCH}$ naive vs preexposed: $t_{(22)}=-0.9, p=0.37 ; 1$-Oct naive vs preexposed: $t_{(22)}=$ $0.1, p=0.92$; 3 -Oct naive vs preexposed: $t_{(22)}=-1.6, p=0.12$; two-sample $t$ test) (Fig. $1 B$ ). To further clarify the contribution of the $\mathrm{CS}^{-}$to the enhanced odor acuity, we asked whether the odor presented as a $\mathrm{CS}^{-}$induced conditioned inhibition independently of the temporal relation to the US. Therefore, we trained the animals again in either an absolute or a differential training regimen (i.e., with or without presenting a $\mathrm{CS}^{-}$), but we tested subsequently for conditioned inhibition in a choice situation between the $\mathrm{CS}^{-}$and a novel, dissimilar odorant (MCH) (Fig. 8C). In the absence of a $\mathrm{CS}^{-}$, the animals significantly avoided the odor that was similar to the $\mathrm{CS}^{+}$, which clearly reflected the generalization across similar odorants (Fig. 8C, white bars).
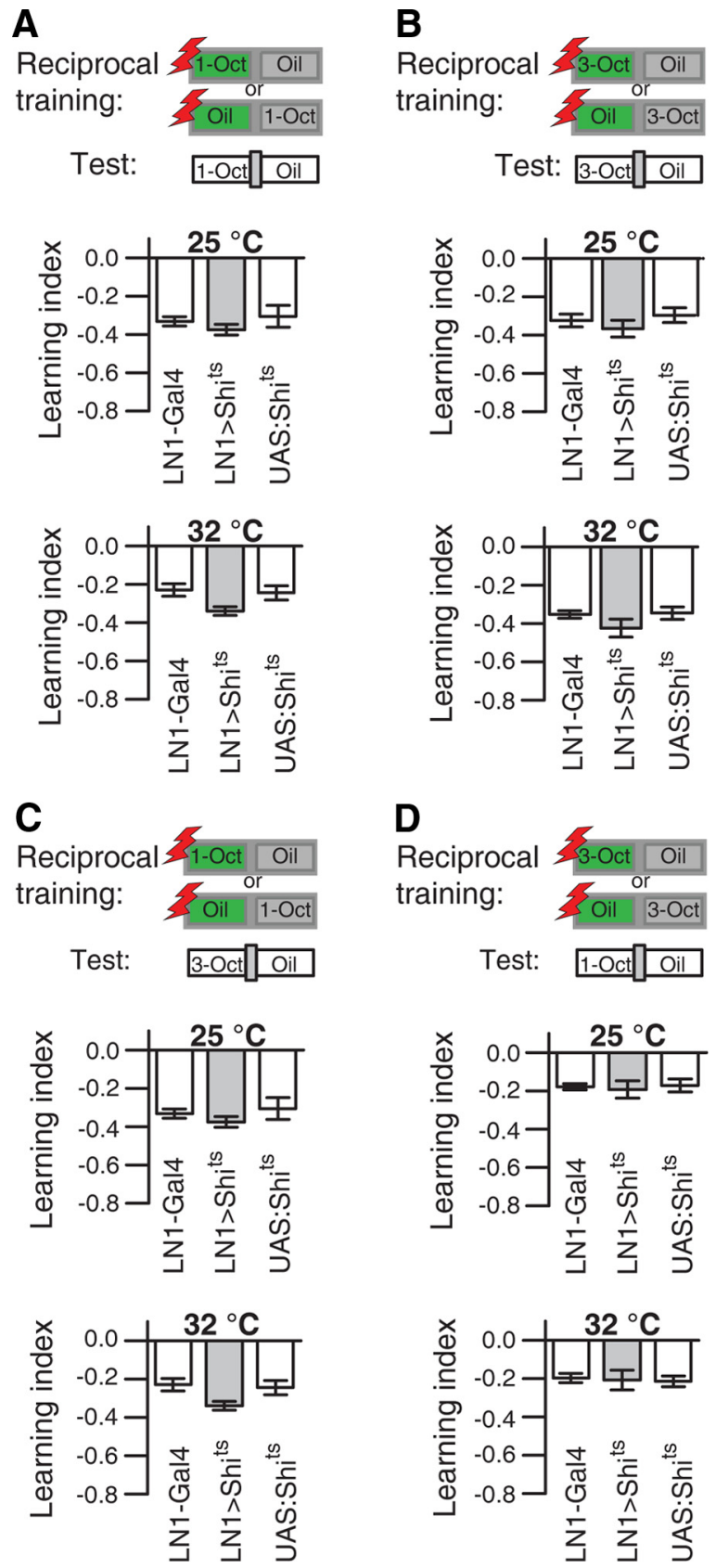

Figure 7. Synaptic output of type I local interneurons (LN1) is not necessary for the association of an odor with electric shocks and generalization across similar odorants. $A, B$, Absolute, reciprocal training with $1-0 \mathrm{ct}(\boldsymbol{A})$ or 3-0ct $(\boldsymbol{B})$ against the diluent was not significantly affected by a temperature-dependent block of synaptic output from local interneurons. One-way ANOVA, $n=8-12$ for each experiment. Bars indicate mean \pm SEM. C, D, Generalization after absolute, reciprocal training of either 1-0ct $(\boldsymbol{C})$ or 3-0ct $(\boldsymbol{D})$ to the similar, but not identical, odorant in a test situation was not significantly $(p>0.05)$ affected by a temperaturedependent block of synaptic output from local interneurons. One-way ANOVA, $n=8-12$ for each experiment. Bars indicate mean \pm SEM.

However, in differential training during which the similar odor was explicitly not paired with the punishment $\left(\mathrm{CS}^{-}\right)$, a significant decrease of this generalization was apparent (Fig. $8 C$, gray bars) (1-Oct absolute vs differential training: $t_{(30)}=-2.8, p<$ 0.01 ; 3-Oct absolute vs differential training: $t_{(30)}=3.0, p<0.01$; two-sample $t$ test). Conclusively, differential training of similar odors comprises not only a conditioned excitation, but also a conditioned inhibition, which can contribute to an enhancement 
A
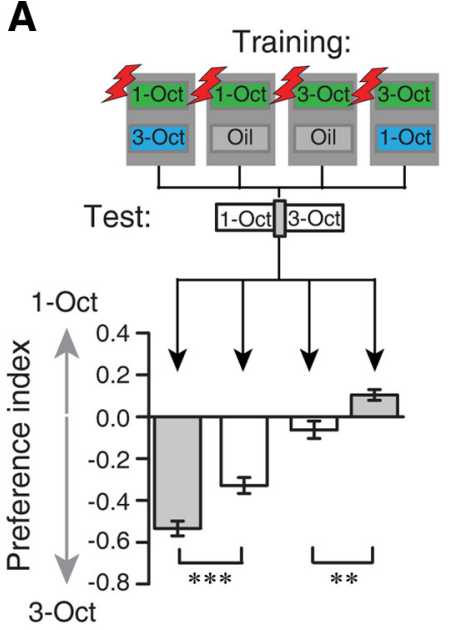

C
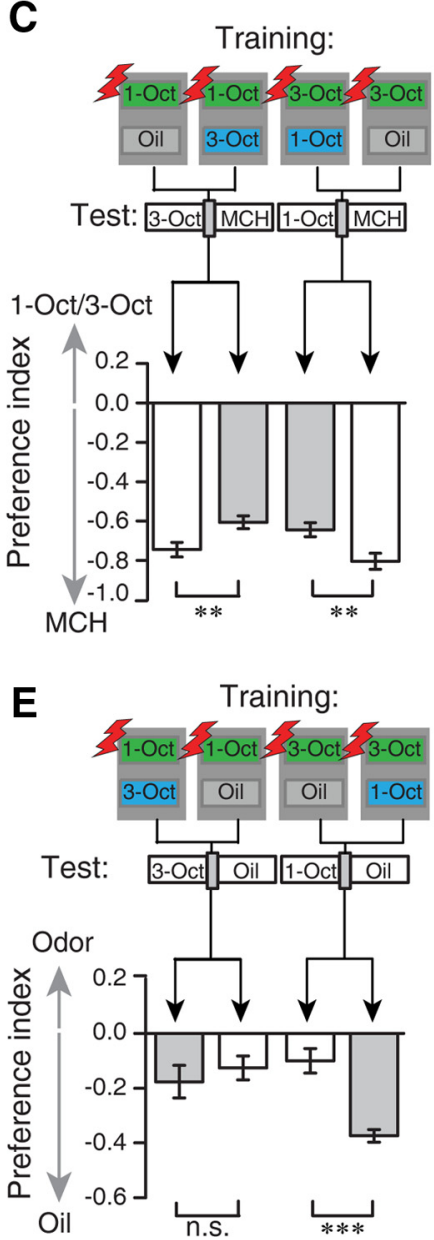

B

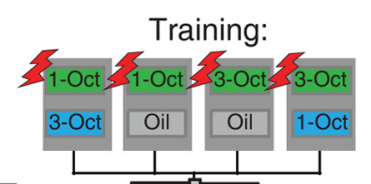

Test:
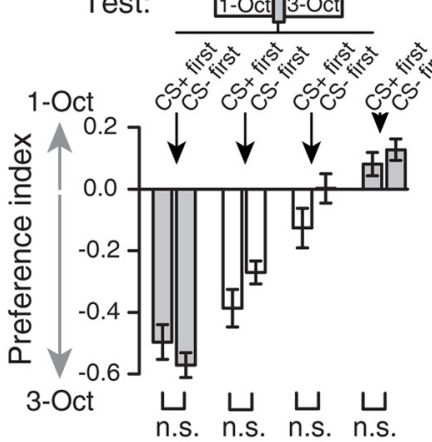

D

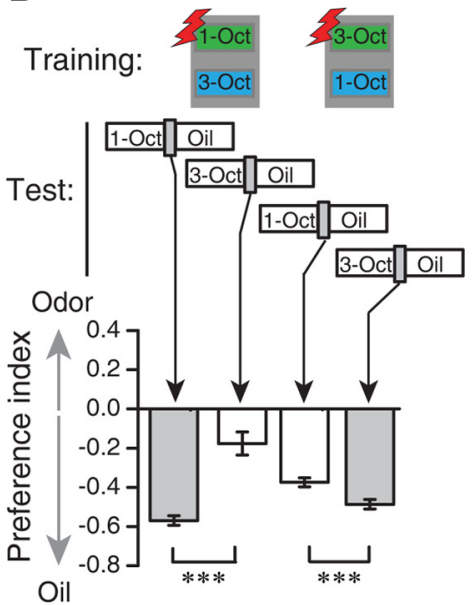

$\mathbf{F}$

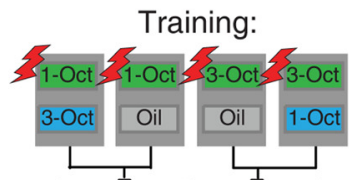

Test:

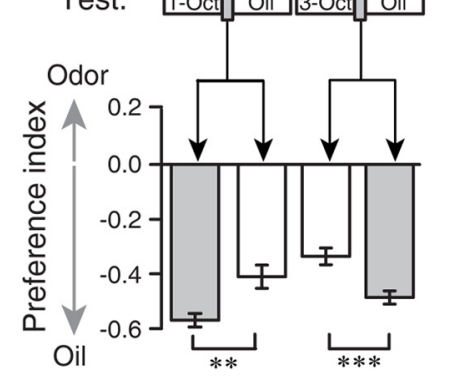

in learned odor discrimination. However, in this experiment, for conditioned inhibition the animals had no choice situation between the similar odors. We wondered whether differential training shifts the balance from generalization across to discrimination between them (Mishra et al., 2010). As an alternative hypothesis, the ability to discriminate in an appropriate choice situation between two similar odors might be independent of the ability to generalize across the similar odors. We subjected the animals to differential training between 1-Oct and 3-Oct and tested them afterward in a choice situation with the $\mathrm{CS}^{+}$versus the diluent only or the $\mathrm{CS}^{-}$versus the diluent, respectively. Not surprisingly, we found that animals strongly avoided the $\mathrm{CS}^{+}$if only this odor was present (Fig. $8 D$, gray bars). However, when tested for the $\mathrm{CS}^{-}$after differential training, the animals still showed a generalized response, although it is significantly smaller (Fig. $8 D$, white bars) (1-Oct CS+ vs $\mathrm{CS}^{-}: t_{(30)}=-6.1, p<0.01 ; 3-\mathrm{Oct} \mathrm{CS}^{+}$ vs CS-: $t_{(30)}=-3.4, p<0.01$; two-sample $t$ test). This response is shown again in Figure $8 E$ (gray bars) in direct comparison with the half-scores after absolute training shown in Figure $1 G, H$. The generalization after differential training with 1-Oct as $\mathrm{CS}^{+}$was not weaker than after absolute training, and it was even stronger when 3-Oct was used as $\mathrm{CS}^{+}$(1-Oct absolute vs differential training: $t_{(30)}=0.7, p=0.5$; 3-Oct absolute vs differential training: $t_{(30)}=5.5, p<0.01$; two-sample $t$ test) (Fig. $8 E$ ). This demonstrates that learned fine odor discrimination (i.e., enhanced olfactory acuity) is behaviorally expressed only if a choice situation between two odors for discrimination exists during the test situation. In other words, flies discriminate only if it is required in the test situation. In test situations in which only one odor is present, a generalized response is observed, independent of the

and 3-0ct and a subsequent test for the nonreinforced odor against the diluent. Whereas the behavior was not different for 1-0ct as a CS ${ }^{+}$, pairing of 3-0ct with electric shocks resulted in a significantly stronger avoidance of 1-0ct after differential training. n.s., Not significant $(p>0.05$; two-sample $t$ test). ${ }^{* * *} p<0.001$ (two-sample $t$ tests). $n=16$ for each experiment. Bars indicate mean \pm SEM. $F$, Comparison of absolute and differential training with 1-0ct and 3-0ct and a subsequent test for the $\mathrm{CS}^{+}$against the diluent. Differential training (gray bars) resulted in a significantly stronger avoidance of the $\mathrm{CS}^{+}$compared with absolute training (white bars). ${ }^{* *} p<0.001$ (two-sample $t$ test). ${ }^{* *} p<0.01$ (twosample $t$ test). $n=16$ for each experiment. Bars indicate mean \pm SEM. 
A<smiles>COOOOC(=O)OCC(=O)O</smiles><smiles>[2H]C(=O)OOOOOOC(=O)O</smiles>

C

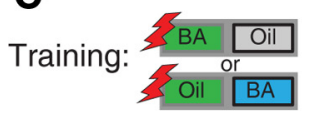

Test: Odor Oil

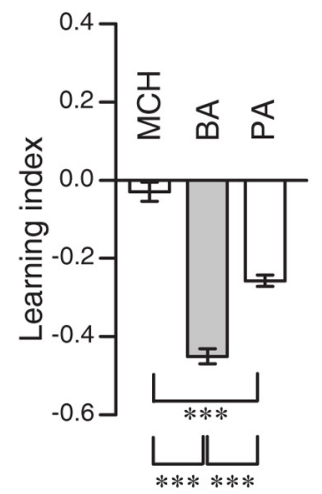<smiles>O=C1C=C(O)COC1</smiles>

4-methylcyclohexanol
B

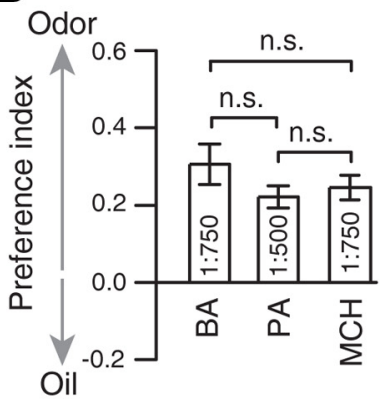

D

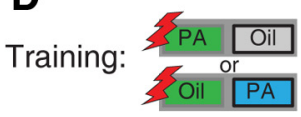

Test: Odor Oil

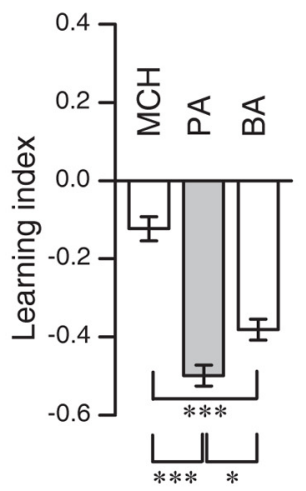

E

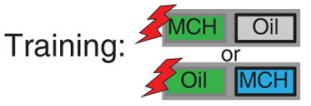

Test: Odor Oil

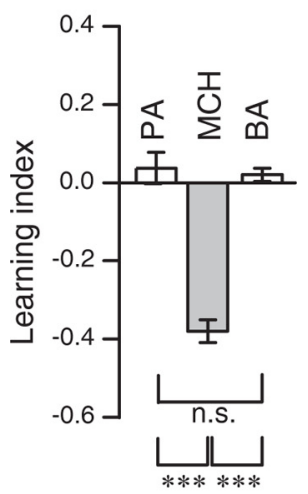

$\mathbf{F}$

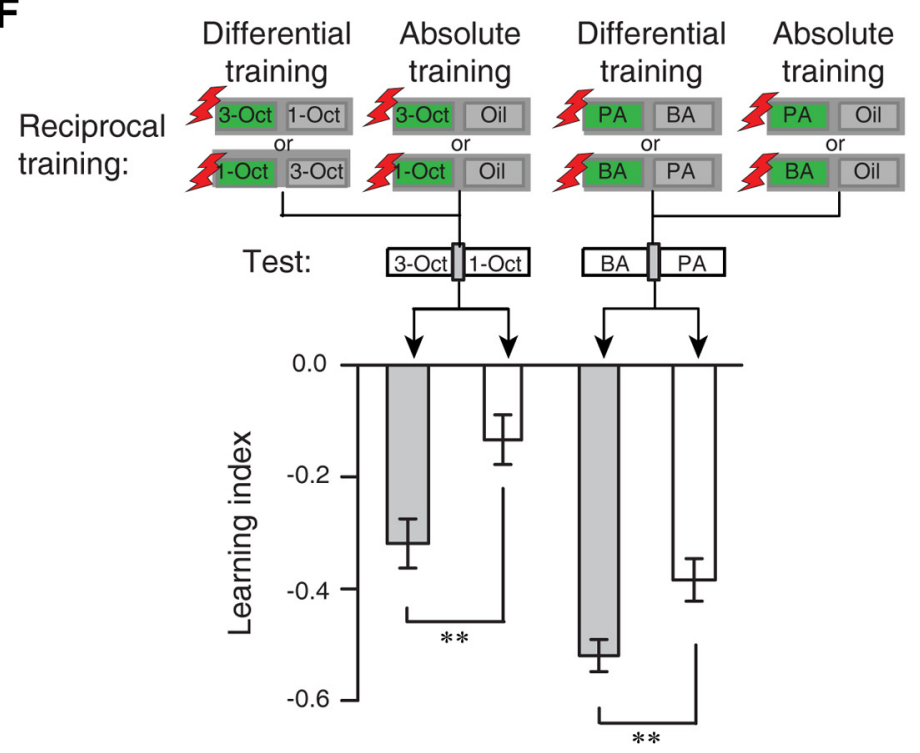

Figure 9. Generalization across a second pair of similar odors. $A$, Chemical structures of the three odorants used: $B A, P A$, and MCH. $\boldsymbol{B}$, Odor preferences of naive flies for the odorants $\mathrm{BA}, \mathrm{PA}$, and $\mathrm{MCH}$ at the dilutions indicated within the bars in a T-maze choice situation against the diluent mineral oil (Oil). No difference between the three odors at the indicated concentrations were observed. n.s., Not significant ( $p>0.05$; one-way ANOVA with Bonferroni post hoc test). Bars indicate mean $\pm \mathrm{SEM} ; n=4-8$ for each experiment. $\boldsymbol{C}-\boldsymbol{E}$, Absolute, reciprocal training of $B A(C, P A(D)$, and $M C H(E)$ against the diluent and test for the avoidance of each odor. In all cases, flies strongly avoided the trained odor (gray bars). Generalization was observed if flies are trained with either BA or PA and tested for the respective similar odor, but not if they were tested for the dissimilar odor $\mathrm{MCH}(C, D)$. Flies did not generalize to $B A$ or $P A$ after training with MCH (E): $n=12$ for each experiment. Bars indicate mean \pm SEM; n.S., Not significant $(p>0.05) ;{ }^{*} p<0.05 ;{ }^{* * *} p<0.001$; one-way ANOVA with Bonferroni post hoc test. $\boldsymbol{F}$, Comparison between preference indices after absolute and differential training. Aversive learning was significantly higher after differential training compared with absolute training, both for the odor pairs 1-0ct/3-0ct (shown also in Fig. $8 A$ ) and BA/PA. ** $p<0.01$ (two-sample t test). $n=32$ for each experiment.

type of previous training. This finding prompted us to analyze the collected data in the opposite context as well. We asked whether differential training, compared with absolute training, changes the response to the $\mathrm{CS}^{+}$if only the $\mathrm{CS}^{+}$is present in the test situation. Interestingly, animals that were subjected to a differential training procedure responded to the $\mathrm{CS}^{+}$with an increased avoidance compared with animals that had been subjected to an absolute training procedure (1-Oct absolute vs differential training: $t_{(30)}=3.3, p<0.01 ; 3$-Oct absolute vs differential training: $t_{(30)}=3.8 ; p<0.01$; two-sample $t$ test) (Fig. 8F). The enhanced olfactory acuity caused by differential training with similar odors is therefore not only based on conditioned inhibition. Rather, during training, the $\mathrm{CS}^{-}$also induces a behavioral contrast that enhances the efficiency of the conditioned excitation (Williams, 2002). As a net result, differential training improves the behavioral discrimination of very similar odors.

To confirm that the observed phenomenon of enhanced acuity caused by differential training of similar odors is not restricted to the single pair of similar odors that we have used throughout this study, we tested a second pair of chemically similar odors, PA and BA (Campbell et al., 2013) (Fig. 9A), at concentrations that evoked equally attractive, naive behavioral responses $\left(F_{(2,16)}=1.2, p=0.33\right.$; one-way ANOVA) (Fig. 9B). The learned behavioral response was strongly generalized to the similar odor in an absolute training regimen (Fig. 9C-E). When BA was trained, an aversive response was evoked also by PA $\left(\mathrm{MCH}\right.$ vs BA: $t_{(22)}=$ $-15.2, p<0.01 ; \mathrm{MCH}$ vs PA: $t_{(22)}=$ $-8.2, p<0.01$; BA vs PA: $t_{(22)}=7.0, p<$ 0.01; one-way ANOVA with Bonferroni post hoc test) (Fig. 9C). Conversely, when PA was trained, an aversive response was evoked also by BA (MCH vs PA: $t_{(22)}=$ $-9.3, p<0.01 ; \mathrm{MCH}$ vs BA: $t_{(22)}=-6.4$, $p<0.01$; BA vs PA: $t_{(22)}=2.9, p<0.05$; one-way ANOVA with Bonferroni post hoc test) (Fig. 9D). However, when $\mathrm{MCH}$ was trained, an aversive response was evoked neither by PA nor by BA ( $\mathrm{MCH}$ vs PA: $t_{(22)}=-9.8, p<0.01$; BA vs PA: $t_{(22)}=-0.4, p=1 ; \mathrm{MCH}$ vs BA: $t_{(22)}=$ $9.3, p<0.01$; one-way ANOVA with Bonferroni post hoc test) (Fig. 9E). However, also for this odor pair, the experience of the similar odor as a $\mathrm{CS}^{-}$in a differential training regimen strongly reduces behavioral generalization (Fig. 9F). Discriminability (i.e., odor acuity) between the 
two odors in the subsequent test situation is enhanced (1-Oct/3Oct absolute vs differential training: $t_{(62)}=-3.0, p<0.01$; BA/PA absolute vs differential training: $t_{(62)}=-2.9, p<0.01$; two-sample $t$ test) (Fig. 9F).

\section{Odor acuity learning causes decorrelation of olfactory representations in Kenyon cells but not in olfactory projection neurons}

After having shown that behaviorally expressed odor similarity is reflected in physiological odor responses in the antennal lobe and that odor acuity is enhanced after a differential conditioning regimen, we asked where in the brain this enhanced odor acuity might be reflected. Physiological changes in odor-evoked $\mathrm{Ca}^{2+}$ responses of OPNs in the antennal lobe of honey bees have been reported after long-term memory formation after differential associative training (Fernandez et al., 2009). This prompted us to investigate odor-evoked $\mathrm{Ca}^{2+}$ responses before and directly after conditioning at the level of the OPNs in the antennal lobe. Flies were subjected to either an absolute (Fig. 10A) or a differential (Fig. 10B) training regimen while fixed under the microscope, and the time courses of odor-evoked $\mathrm{Ca}^{2+}$-activity were measured before and after the training in each fly (Fig. 10A,B). To investigate possible changes in similarity of odor representations, we calculated the principal components of the mean odorevoked responses in olfactory projection neurons over time (Fig. $10 C$ ) and the Pearson's correlations during the stimulus (Fig. $10 D)$ before and after training for absolute and differential conditioning. No significant differences between the correlation coefficients before and after training could be observed for either of the training paradigms (pretraining absolute vs differential training: $p=0.09 ; U=27 ; Z=-1.7$; post-training absolute vs differential training: $p=0.16 ; U=31 ; Z=-1.4$; Mann-Whitney $\mathrm{U}$ test).

We next asked whether the similarity between neuronal populations detected in the antennal lobe is maintained at higher olfactory processing centers. A broad wealth of data indicates that the coincidence detection between odor (CS) and punishment (US) as well as subsequent neuronal changes mediating the learned behavioral response can be, at least partially, localized to Kenyon cell output synapses (for review, see Heisenberg, 2003; Fiala, 2007). We first asked whether the similarity of the neuronal representation detected in the antennal lobe is maintained at the level of mushroom body lobes and, second, whether the similarity is altered by absolute or differential training. We expressed the $\mathrm{Ca}^{2+}$ sensor protein GCaMP3.0 (Tian et al., 2009) under direct control of the mushroom body-specific promoter mb247 (Pech et al., 2013). The expression induced by two copies of the mb247 promoter fragment covers all mushroom body lobes and subtypes of Kenyon cells (Fig. 11A,B). Two subpopulations of Kenyon cells in the mushroom body have been suggested as being particularly important for olfactory learning. On the one hand a change in neuronal activity due to learning has been visualized using $\mathrm{Ca}^{2+}$ imaging in the $\alpha^{\prime} / \beta^{\prime}$-lobes (Wang et al., 2008). On the other hand, a genetic rescue, mainly in the $\gamma$-lobes, of the rutabaga gene restores impaired short-term memory (Zars et al., 2000). Furthermore, a genetic rescue of the loss of a D1-like dopamine receptor in the $\gamma$-lobes likewise restores learning deficits (Qin et al., 2012). Therefore, we have chosen to focus on the $\beta$ 'and $\gamma$-lobes that could be observed simultaneously on the same focal plane (Fig. $11 A, B$ ). Odor-evoked $\mathrm{Ca}^{2+}$ transients in the bundled, axon-like neurites of Kenyon cells furnished with presynapses and postsynapses forming the horizontal lobes were reliably detectable. The three odorants 1-Oct, 3-Oct and $\mathrm{MCH}$ evoked activity patterns in Kenyon cell neurites constituting the $\gamma$ - and $\beta$ '-lobes (Fig. 11C). Odor-evoked $\mathrm{Ca}^{2+}$ activity in the $\gamma$-lobes was much weaker in amplitude than in the $\beta$ '-lobes (Fig. $11 C, D, G)$. This is in agreement with the report that $\gamma$-type Kenyon cells have higher firing thresholds at their input sites (Turner et al., 2008). The odor-evoked $\mathrm{Ca}^{2+}$ activity patterns in each fly were, however, not stereotypic or comparable in spatial distribution across animals, in agreement with the reported nonstereotypic odor representations in Kenyon cells (Murthy et al., 2008; Caron et al., 2013). Therefore, we performed a pixel-based, within-animal comparison to quantify how the spatial activity patterns evoked by the three odors correlated to each other. We found that the $\mathrm{Ca}^{2+}$ activity patterns within each measured fly induced by 1-Oct and by 3-Oct, respectively, correlated more strongly to each other than the responses to the pairs of dissimilar odors (i.e., 1-Oct and $\mathrm{MCH}$ or 3-Oct and $\mathrm{MCH}$, respectively), in both the $\beta^{\prime}$-lobes $\left(\mathrm{MCH} / 3\right.$-Oct vs $\mathrm{MCH} / 1$-Oct: $t_{(38)}=1.1, p=$ $0.84 ; \mathrm{MCH} / 3$-Oct vs 3-Oct/1-Oct: $t_{(38)}=9.2, p<0.01 ; \mathrm{MCH} / 1-$ Oct vs 3-Oct/1-Oct: $t_{(38)}=8.1, p<0.01$; one-way repeatedmeasures ANOVA with Bonferroni post hoc test) (Fig. 11E) and the $\gamma$-shaft $\left(\mathrm{MCH} / 3\right.$-Oct vs MCH/1-Oct: $t_{(38)}=2.0, p=0.16$; $\mathrm{MCH} / 3$-Oct vs 3-Oct/1-Oct: $t_{(38)}=10.2, p<0.01 ; \mathrm{MCH} / 1-\mathrm{Oct}$ vs 3-Oct/1-Oct: $t_{(38)}=8.2, p<0.01$; one-way repeated-measures ANOVA with Bonferroni post hoc test) (Fig. 11H). In conclusion, the similarity/dissimilarity between odor representations manifested at the level of the antennal lobes is maintained at the level of the mushroom body lobes. We next asked whether the learned, enhanced odor acuity is reflected in the odor response pattern within the Kenyon cell neurites. Therefore, after initial odor responses were recorded, the flies were subjected to either absolute or differential conditioning directly under the microscope, and odor responses were recorded again afterward. Paralleling the behavioral experiments, half of the animals of each training group were trained using 3-Oct as $\mathrm{CS}^{+}$(and 1-Oct as the $\mathrm{CS}^{-}$in the differential training regimen), the other half of the animals were trained using 1-Oct as the $\mathrm{CS}^{+}$. Again, the dissimilar odor $\mathrm{MCH}$ served as a control odor and was presented before and after, but not during, conditioning. We did not detect any significant difference in similarity of odor representations of the two similar odors, in the $\beta^{\prime}$-lobes, either when comparing initial odor responses or when comparing postconditioning responses of either absolutely or differentially trained flies, respectively (pretraining absolute vs differential training: $p=0.68 ; U=56$; $Z=0.4$; post-training absolute vs differential training: $p=$ $0.12 ; U=71 ; Z=1.6$; Mann-Whitney U test) (Fig. $11 F$ ). However, when the same analysis of odor responses was performed for the $\gamma$-shaft and the correlation between the neuronal representations evoked by the trained, similar odors was calculated, we found a significant decorrelation after differential conditioning (pretraining absolute vs differential training: $p=0.24 ; U=66 ; Z=1.2$; post-training absolute vs differential training: $p<0.05 ; U=83 ; Z=2.5$; Mann-Whitney $U$ test) (Fig. 11I). The change in odor acuity cause by differential training is therefore reflected in the similarity of odor representations at the level of the $\gamma$-lobes of the mushroom body.

\section{Discussion}

How is perceptual similarity between odors encoded?

In fruit flies, several neuronal "labeled-line" pathways have evolved to detect, using narrow-tuned receptors, ecologically relevant odors exclusively and unambiguously, for instance, pheromones (Ha and Smith, 2006; Kurtovic et al., 2007), $\mathrm{CO}_{2}$ (Suh et 
A

Absolute Training

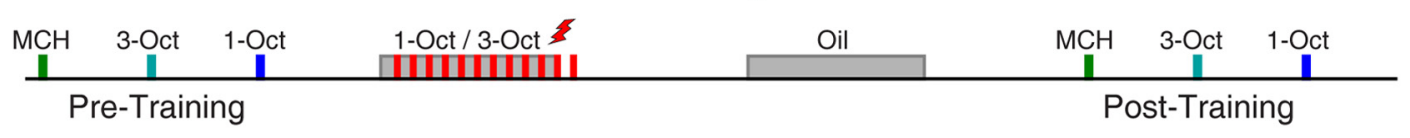
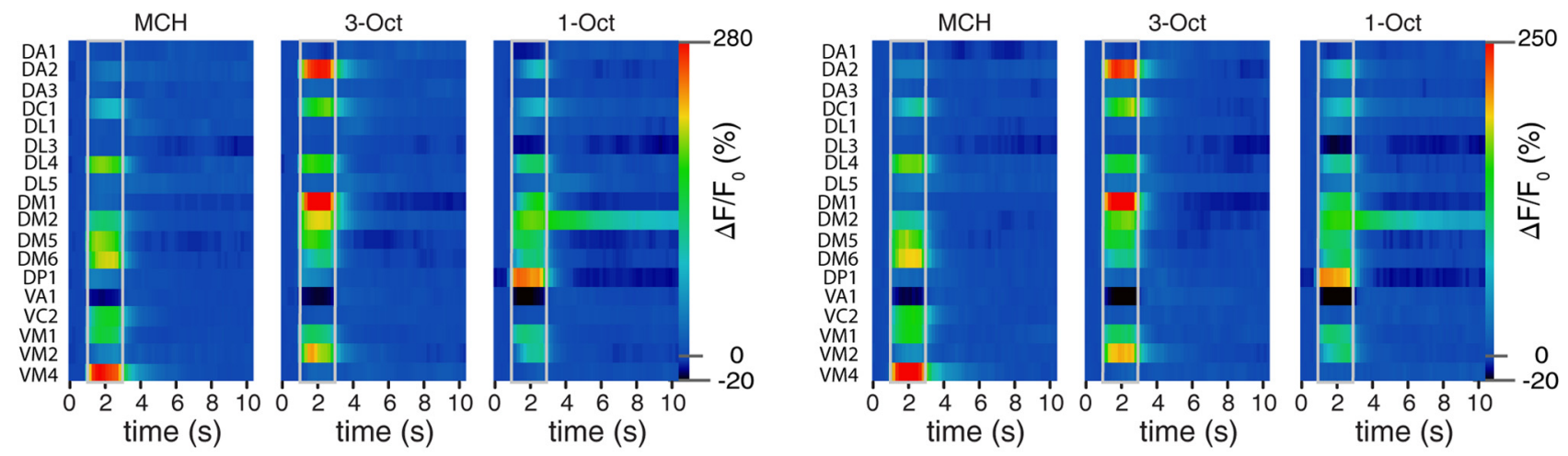

B

Differential Training
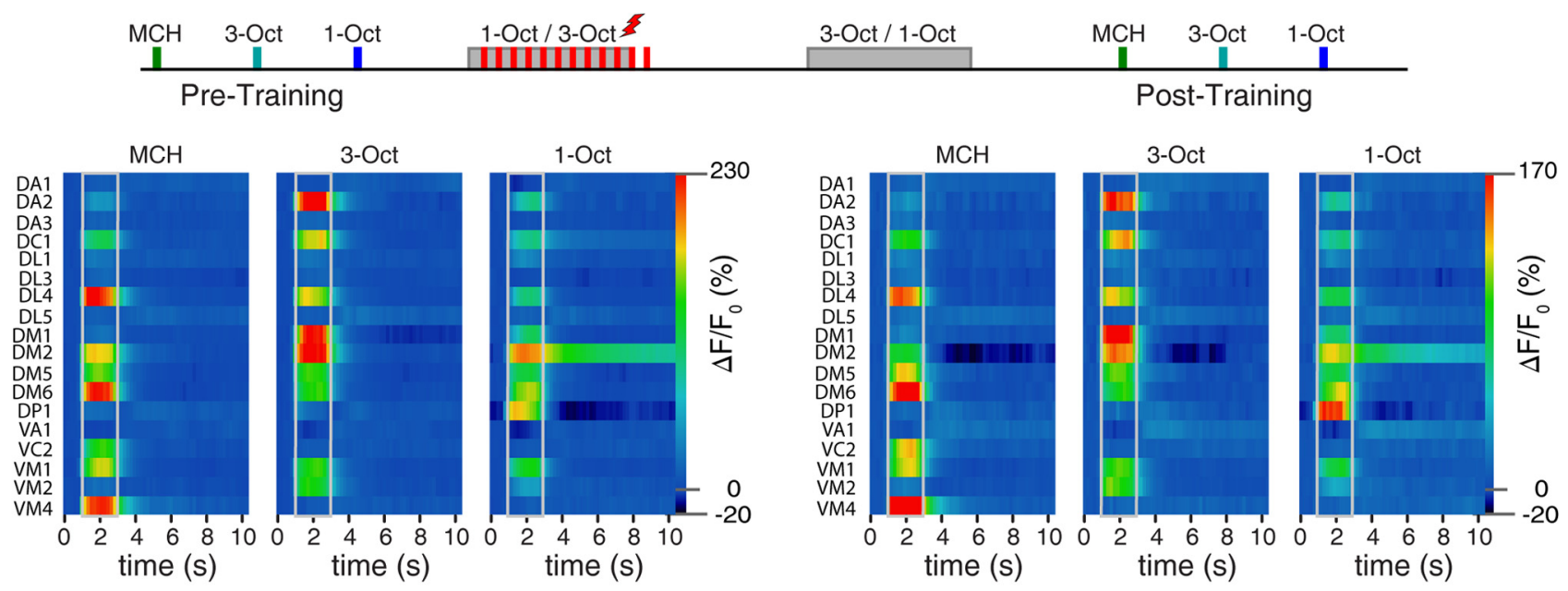

C

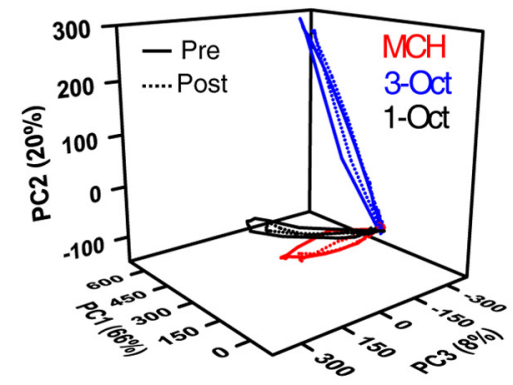

Differential Training

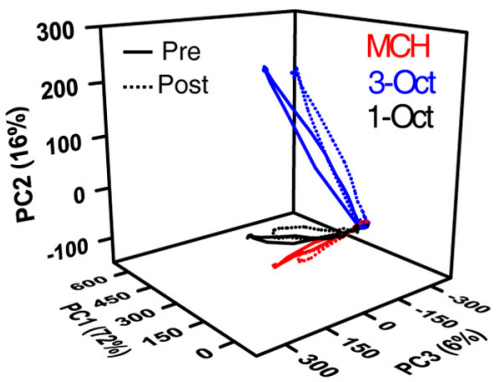

D

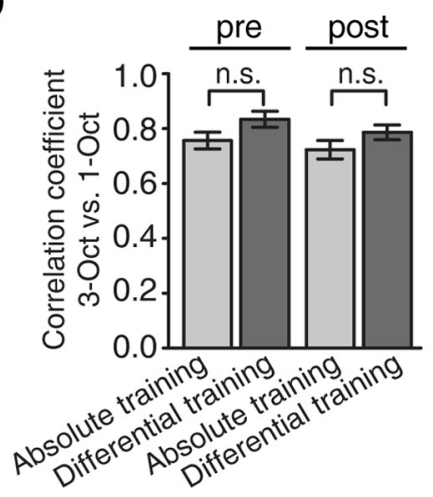

Figure 10. The spatiotemporal $\mathrm{Ca}^{2+}$ activity in olfactory projection neurons at the level of the antennal lobe evoked by two similar odors is not affected by differential or absolute conditioning. $\boldsymbol{A}$, Schematic illustration of the absolute conditioning regimen applied to the prepared fly positioned under the microscope. Bottom, 0 dor-evoked changes ${ }^{2+}{ }^{2+}$ activity over time are shown as false colors in 18 identified glomeruli in response to the odorants $\mathrm{MCH}, 3-0 \mathrm{ct}$, and 1-0ct before and after training, respectively. Left, Pretraining glomerular activation. Right, Post-training. Gray lines indicate odor onset and offset. Values indicate mean; $n=10$ animals. $\boldsymbol{B}$, Schematic illustration of the differential conditioning regimen applied to the prepared fly positioned under the microscope. Bottom, 0 dor-evoked changes $\mathrm{Ca}^{2+}$ activity over time are shown as false colors in 18 identified glomeruli in response to the odorants $\mathrm{MCH}, 3-0 \mathrm{ct}$, and 1-0ct before and after training, respectively. Left, Pretraining glomerular activation. Right, Post-training. Gray lines indicate odor onset and offset. Values indicate mean; $n=10$ animals. C, PCA of the time courses of the mean odor-evoked responses in olfactory projection neurons before training (solid lines) and after training (dotted lines) for absolute conditioning (left) and for differential conditioning (right). The first three principal components covered $>94 \%$ of the variance. $D$, Pearson's correlation coefficients between the similar odors 1-0ct and 3-0ct before and after absolute or differential conditioning. No significant differences (n.S., Not significant; $p>0.05$; Mann-Whitney $\mathrm{U}$ test, $n=10$ each) between absolute and differential training were observed. Bars indicate mean $\pm \mathrm{SEM}$. 
A

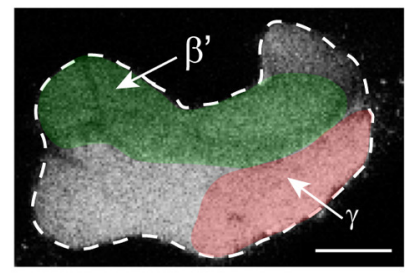

C

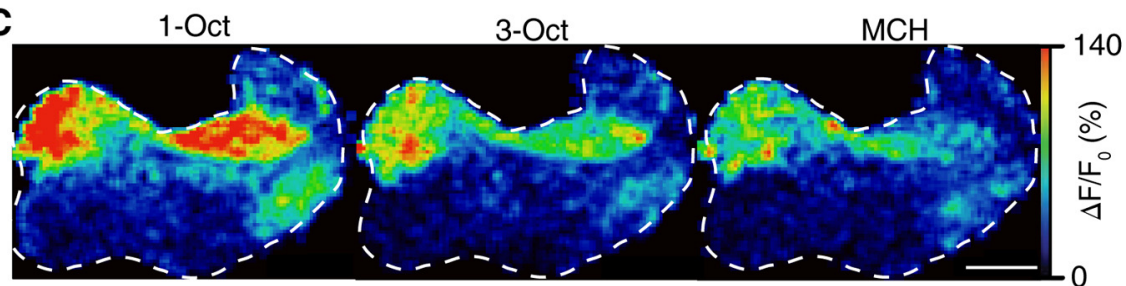

D

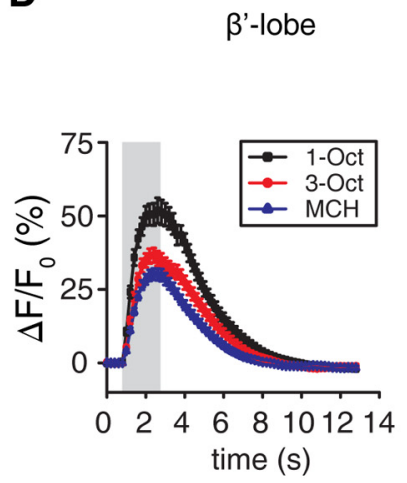

G

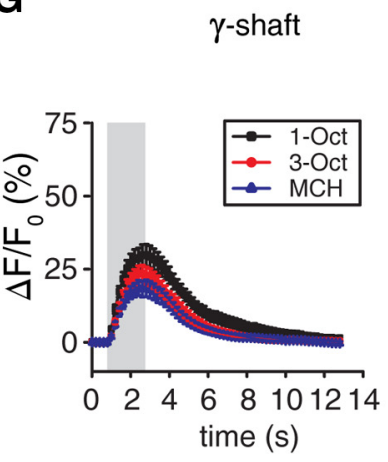

B

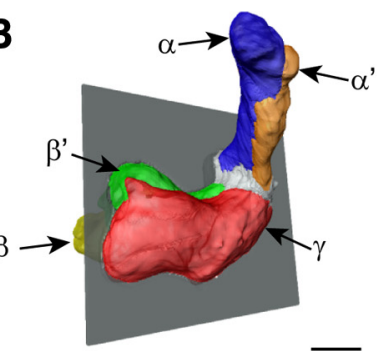

$\mathbf{E}$
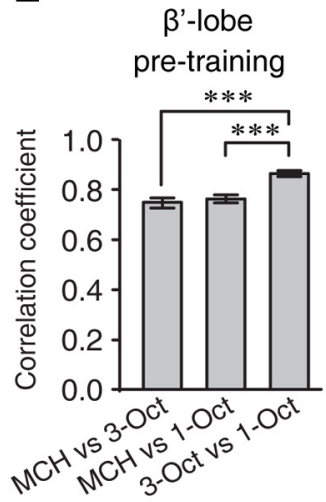

H

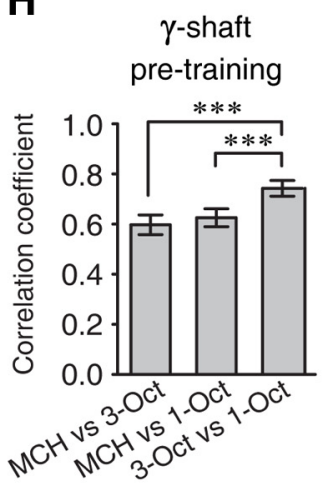

$\mathbf{F}$

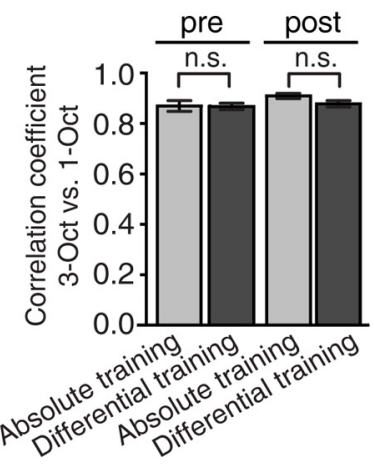

I

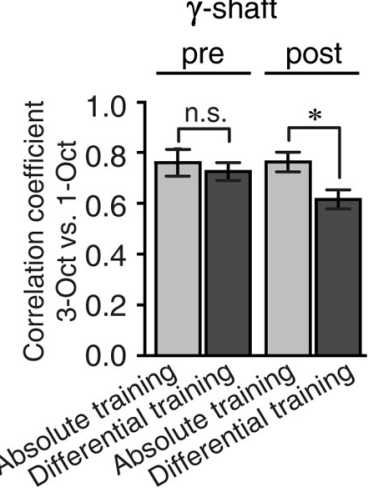

Figure 11. Dynamics and similarity of odor representations in the mushroom body. $A$, Expression of the $\mathrm{Ca}^{2+}$ sensor GCaMP3.0 in the mushroom body shown in the focal plane chosen for imaging in the horizontal lobes of the mushroom body. The focal plane includes the $\gamma$-lobe and the $\beta^{\prime}$-lobe. Red represents the $\gamma$-shaft region; green represents the $\beta^{\prime}$-region. $\boldsymbol{B}, 3 \mathrm{D}$ reconstruction of parts of a mushroom body based on GCaMP3.0 expression in Kenyon cells of one fly used during an optical $\mathrm{Ca}^{2+}$ imaging experiment. Different colors represent distinct lobes. Gray represents the focal plane chosen for imaging. $\mathrm{C}_{1} \mathrm{Ca}^{2+}$ increase in the focal plane shown in $\boldsymbol{A}$ and $\boldsymbol{B}$ is evoked by stimulation with 1-0ct, 3-0ct, and $M C H$, as indicated in false colors. Scale bars: $\boldsymbol{A}-\boldsymbol{C}, 20$ $\mu \mathrm{m}$. $\boldsymbol{D}$, Temporal dynamics of odor-evoked changes in fluorescence averaged over the $\beta^{\prime}$-lobe region in response to presentation of 1-0ct, 3-0ct, or MCH. The gray bar represents the duration of odor stimulation. Values indicate mean $\pm \mathrm{SEM} ; n=20$. $E$, The $\mathrm{Ca}^{2+}$ signals evoked by the pair of similar odors in the $\beta^{\prime}$-lobe correlate significantly stronger than those evoked by the dissimilar odor pairs. Bars indicate mean \pm SEM of pixel-based Pearson's correlation coefficients. $n=20$. ${ }^{* *} p<0.001$ (one-way repeatedmeasures ANOVA with Bonferroni post hoc test). $\boldsymbol{F}$, Pearson's correlation coefficients as measured in the $\beta^{\prime}$-lobe between the similar odors 1-0ct and 3-0ct before and after absolute or differential conditioning. No significant differences (n.s., Not significant; $p>0.05$; Mann-Whitney $\mathrm{U}$ test, $n=10$ each) between absolute and differential training were observed. G, Temporal dynamics of odor-evoked changes in fluorescence averaged over the $\gamma$-shaft region in response to presentation of 1-0ct, 3-0ct, or MCH. The gray bar represents the duration of odor stimulation. Values indicate mean $\pm \mathrm{SEM} ; n=20 . \boldsymbol{H}$, The $\mathrm{Ca}^{2+}$ signals evoked by the pair of similar odors in the $\gamma$-shaft correlate significantly stronger than those evoked by the dissimilar odor pairs. Bars indicate mean \pm SEM of pixel-based Pearson's correlation coefficients. $n=20 .{ }^{* * *} p<0.001$ (one-way repeated-measures ANOVA with Bonferron

al., 2004; Jones et al., 2007; Suh et al., 2007), or the mold odor, geosmin (Stensmyr et al., 2012), to elicit behavior. For all odors whose relevance is not innately predetermined, more plastic recognition mechanisms must exist that take stimulus variations into account. Learned relevance can be transferred to similarly perceived odors through generalization, a phenomenon that has been well described for olfactory learning in adult and larval Drosophila (Eschbach et al., 2011; Niewalda et al., 2011; Mishra et al., 2010; Chen YC, et al., 2011). We have chosen chemically similar odorants based on previous reports (Mishra et al., 2010; Campbell et al., 2013) and found a high degree of generalization between them. But how is perceived similarity manifested in the fly's brain? Odor-evoked glomerular activity is, at the level of the insect antennal lobe, rather stereotypic across individuals (e.g., Fiala et al., 2002; Couto et al., 2005; Fishilevich and Vosshall, 2005). The overlap in the activity pattern of glomeruli of the antennal lobe or the mammalian olfactory bulb, respectively, has been regarded as a correlate of chemical odorant similarity (Meister and Bonhoeffer, 2001; Belluscio and Katz, 2001; Johnson et al., 2009), and behaviorally determined odor similarity (Guerrieri et al., 2005; Kreher et al., 2008; Youngentob et al., 2006; Niewalda et al., 2011; Parnas et al., 2013), which is in accordance with our results. Interestingly, in Drosophila the spatial activity patterns of second-order OPNs in the antennal lobes match perceived odor similarity more closely than those of first-order OSNs (Niewalda et al., 2011), and the activity of OPNs correlates with innate odor discriminability (Parnas et al., 2013). In the course of transforming odor information from first- to second-order neurons, inhibitory local interneurons (LNs) have been suggested as a cause of fine-tuning of spatiotemporal activity patterns (Stopfer et al., 1997; Sachse and Galizia, 2002; Wilson et al., 2004; Wilson and Laurent, 2005), which might ultimately contribute to the discriminability between similar odors. In accordance with that idea, pharmacological interference with GABA receptors in the antennal lobes of honeybees disrupts local field potential oscillations caused by synchro-

$\leftarrow$

posthoc test). I, Pearson's correlation coefficients as measured in the $\gamma$-shaft between the similar odors 1-0ct and 3-0ct before and after absolute or differential conditioning, respectively. A significant decorrelation between the two similar odors (n.s., Not significant; $p>0.05 ;{ }^{*} p<0.05$; Mann-Whitney $U$ test, $n=10$ each) was observed after differential training compared with absolute training. 
nized projection neurons and impairs fine discrimination between similar odors (Stopfer et al., 1997). We find that type I inhibitory LNs of the antennal lobe, which target OPNs and not OSNs (Tanaka et al., 2009), are required for fine discrimination of similar odors in Drosophila. However, in Drosophila, type I LNs are not required to maintain the synchrony of projection neurons, in contrast to type II LNs (Tanaka et al., 2009). In conclusion, the role of these inhibitory LNs for fine odor discrimination does not rely on synchronizing projection neuron activity. Lateral inhibition between glomeruli has also been suggested as a mechanism for fine odor discrimination (Sachse and Galizia, 2002; Wilson and Laurent, 2005), which can explain our results. Interestingly, the correlation between similar odorants, behaviorally expressed similarity, and odor-evoked spatial neuronal activity is maintained in the activity of intrinsic mushroom body neurons (Kenyon cells) in accordance with reports of $\mathrm{Ca}^{2+}$ transients detected in Kenyon cell somata (Campbell et al., 2013).

\section{What is learned in conditioned fine odor discrimination?}

Flies can clearly learn to differentiate various concentrations of odors (Masek and Heisenberg, 2008), combinations of binary odor mixtures (Eschbach et al., 2011; Borst, 1983), and a large number of diverse chemicals (Dudai, 1977). Olfactory responsiveness is modulated by several intrinsic or environmental factors, for instances, circadian rhythm (Krishnan et al., 1999), feeding status (Itskov and Ribeiro, 2013), or ambient temperature (Riveron et al., 2009), which all could lead to altered olfactory acuity. These influences can be experimentally distinguished from learned changes in olfactory acuity. It has been suggested that, in Drosophila, the presentation of the $\mathrm{CS}^{-}$has no influence during the formation of an associative odor memory (Borst, 1983; Masek and Heisenberg, 2008). Rather, only the exposure to the $\mathrm{CS}^{+}$simultaneously with the reinforcement has been proposed to cause learning, as reflected in respective cellular models of associative odor learning (Heisenberg, 2003; Fiala, 2007). We reasoned that neuronal mechanisms underlying learned fine odor discrimination might not be assessable using very high odor concentrations and chemically dissimilar odors. Here we show that, if two similar odors are used as $\mathrm{CS}^{+}$and $\mathrm{CS}^{-}$, respectively, exposure to the $\mathrm{CS}^{-}$causes conditioned inhibition that contributes to an enhanced discrimination (i.e., an improved olfactory acuity of initially confusable odors). Fruit flies can exhibit odorspecific learning strategies (e.g., Yarali et al., 2009). However, we have observed learned enhancement of odor acuity with two chemically similar pairs of odorants, suggesting that this phenomenon is not restricted to specific odorants. This new finding cannot be mechanistically explained by current cellular models of olfactory learning (Heisenberg, 2003; Busto et al., 2010). Interestingly, the effect of the $\mathrm{CS}^{-}$is not equivalent to inhibitory learning caused by backward conditioning (Tanimoto et al., 2004), as the conditioned inhibition found in our study is independent of the exact timing of the $\mathrm{CS}^{-}$presentation relative to the US. Conclusively, maintenance of odor representations over the training period has to be proposed. Indeed, trace conditioning experiments in flies and bees have demonstrated that odor representations can be maintained (Galili et al., 2011; Szyszka et al., 2011). Interestingly, the presence of the $\mathrm{CS}^{-}$during differential training not only induces a conditioned inhibition but enhances also the learned responsiveness to the $\mathrm{CS}^{+}$, a phenomenon known as behavioral contrast (Williams, 2002). Based on this finding, we have to assume an influence of the $\mathrm{CS}^{-}$on the $\mathrm{CS}^{+}$representation and/or reinforcement efficiency. A number of theoretical explanations for behavioral contrast have been formulated (Williams, 2002). The difference in learned behavior dependent on the presentation of a $\mathrm{CS}^{-}$can either be regarded as a consequence of the experience of the $\mathrm{CS}^{-}$in the differential training regimen, or, conversely, as a lack of experience in the absolute training regimen (i.e., a novelty effect). The genetic and physiological tools available in Drosophila might help to further dissect the neuronal basis for this phenomenon.

We find that generalization between the two similar odors is nearly symmetric in strength (i.e., absolute training of either odor results in similar avoidance of the other odor). However, discrimination of the two odorants after differential training is not symmetric: If 1-Oct is temporally paired with electric shocks and 3 -Oct is not, 1-Oct is strongly avoided in a choice situation between the two odors. The reciprocal situation, however, is much less pronounced. This asymmetry might be explained by the neuronal, glomerular representations at the level of OSNs, as the representation of 3-Oct is "nested" within the 1-Oct representation. From a theoretical viewpoint, this can be regarded as a "negative patterning problem," which has been reported to be more difficult for flies to solve through associative learning than positive patterning in which the nonoverlapping representation is reinforced (Young et al., 2011).

\section{Neural systems for olfactory acuity learning: common principles across species?}

Decades of research have led to the current concept of a coincidence detection between odor (CS) information and punishment (US) information in Kenyon cells (Heisenberg, 2003; Fiala, 2007). Conclusively, the essential memory trace for associative odor learning can be localized in Kenyon cells. Here we show that acuity learning of similar odors causes decorrelation of odor representation in the $\gamma$-lobes of the mushroom body. Whereas learning-induced changes in synaptic transmission in the antennal lobe in Drosophila (Yu et al., 2004), and changes in $\mathrm{Ca}^{2+}$ dynamics correlating with long-term memory in bees (Fernandez et al., 2009) have been described, we do not find short-term changes in odor-evoked $\mathrm{Ca}^{2+}$ representations in OPNs resulting from differential training of similar odors.

Interestingly, neuronal mechanisms underlying olfactory acuity learning in Drosophila are similar to those in mammals. Associative learning of olfactory acuity in rodents changes response properties of piriform cortical neurons in such that discriminability of similar odors is, at a cellular level, enhanced (Litaudon et al., 1997; Kadohisa and Wilson, 2006; Chapuis and Wilson, 2011; Chen CF, et al., 2011). The mushroom body resembles the piriform cortex of mammals in several features. Kenyon cells each receive input from many different projection neurons (Caron et al., 2013; Gruntman and Turner, 2013), similarly to pyramidal cells of the anterior piriform cortex (Sosulski et al., 2011), thereby integrating information originating in many olfactory receptors. Furthermore, Kenyon cells respond to odors in a sparse, highly selective way, and any spatial, chemotopic information has been suggested to be eliminated at this level of processing (Murthy et al., 2008; Turner et al., 2008; Honegger et al., 2011), similarly to piriform cortex neurons (Stettler and Axel, 2009). Comparable functions of the mushroom body and the piriform cortex are therefore certainly conceivable. Our data demonstrate that differential associative training can affect olfactory acuity in a bidirectional way also in Drosophila and that this is not a property restricted to the brains of higher vertebrates.

\section{References}

Armstrong JD, Kaiser K, Müller A, Fischbach KF, Merchant N, Strausfeld NJ (1995) Flybrain, an on-line atlas and database of the Drosophila nervous system. Neuron 15:17-20. CrossRef Medline 
Belluscio L, Katz LC (2001) Symmetry, stereotypy, and topography of odorant representations in mouse olfactory bulbs. J Neurosci 21:2113-2122. Medline

Bitterman ME, Menzel R, Fietz A, Schäfer S (1983) Classical conditioning of proboscis extension in honeybees (Apis mellifera). J Comp Psychol 97: 107-119. CrossRef Medline

Borst A (1983) Computation of olfactory signals in Drosophila melanogaster. J Comp Physiol 152:373-383.

Busto GU, Cervantes-Sandoval I, Davis RL (2010) Olfactory learning in Drosophila. Physiology (Bethesda) 25:338-346. CrossRef Medline

Campbell RA, Honegger KS, Qin H, Li W, Demir E, Turner GC (2013) Imaging a population code for odor identity in the Drosophila mushroom body. J Neurosci 33:10568-10581. CrossRef Medline

Caron SJ, Ruta V, Abbott LF, Axel R (2013) Random convergence of olfactory inputs in the Drosophila mushroom body. Nature 497:113-117. CrossRef Medline

Chapuis J, Wilson DA (2011) Bidirectional plasticity of cortical pattern recognition and behavioral sensory acuity. Nat Neurosci 15:155-161. CrossRef Medline

Chen CF, Barnes DC, Wilson DA (2011a) Generalized vs stimulus-specific learned fear differentially modifies stimulus encoding in primary sensory cortex of awake rats. J Neurophysiol 106:3136-3144. CrossRef Medline

Chen YC, Mishra D, Schmitt L, Schmuker M, Gerber B (2011) A behavioral odor similarity "space" in larval Drosophila. Chem Senses 36:237-249. CrossRef Medline

Chou YH, Spletter ML, Yaksi E, Leong JC, Wilson RI, Luo L (2010) Diversity and wiring variability of olfactory local interneurons in the Drosophila antennal lobe. Nat Neurosci 13:439-449. CrossRef Medline

Cleland TA, Morse A, Yue EL, Linster C (2002) Behavioral models of odor similarity. Behav Neurosci 116:222-231. CrossRef Medline

Couto A, Alenius M, Dickson BJ (2005) Molecular, anatomical, and functional organization of the Drosophila olfactory system. Curr Biol 15:15351547. CrossRef Medline

Davis RL (1993) Mushroom bodies and Drosophila learning. Neuron 11:114. CrossRef Medline

Dudai Y (1977) Properties of learning and memory in Drosophila melanogaster. J Comp Physiol A Neuroethol Sens Neural Behav Physiol 114:6989. CrossRef

Eschbach C, Vogt K, Schmuker M, Gerber B (2011) The similarity between odors and their binary mixtures in Drosophila. Chem Senses 36:613-621. CrossRef Medline

Fernandez PC, Locatelli FF, Person-Rennell N, Deleo G, Smith BH (2009) Associative conditioning tunes transient dynamics of early olfactory processing. J Neurosci 29:10191-10202. CrossRef Medline

Fiala A (2007) Olfaction and olfactory learning in Drosophila: recent progress. Curr Opin Neurobiol 17:720-726. CrossRef Medline

Fiala A, Spall T, Diegelmann S, Eisermann B, Sachse S, Devaud JM, Buchner E, Galizia CG (2002) Genetically expressed cameleon in Drosophila melanogaster is used to visualize olfactory information in projection neurons. Curr Biol 12:1877-1884. CrossRef Medline

Fishilevich E, Vosshall LB (2005) Genetic and functional subdivision of the Drosophila antennal lobe. Curr Biol 15:1548-1553. CrossRef Medline

Fletcher ML, Wilson DA (2002) Experience modifies olfactory acuity: acetylcholine-dependent learning decreases behavioral generalization between similar odorants. J Neurosci 22:RC201. Medline

Galili DS, Lüdke A, Galizia CG, Szyszka P, Tanimoto H (2011) Olfactory trace conditioning in Drosophila. J Neurosci 31:7240-7248. CrossRef Medline

Ghirlanda S, Enquist M (2003) Reviews: a century of generalisation. Anim Behav 66:15-36. CrossRef

Giurfa M (2004) Conditioning procedure and color discrimination in the honeybee Apis mellifera. Naturwissenschaften 91:228-231. CrossRef Medline

Gruntman E, Turner GC (2013) Integration of the olfactory code across dendritic claws of single mushroom body neurons. Nat Neurosci 16: 1821-1829. CrossRef Medline

Guerrieri F, Schubert M, Sandoz JC, Giurfa M (2005) Perceptual and neural olfactory similarity in honeybees. PLoS Biol 3:e60. CrossRef Medline

Guizar-Sicairos M, Thurman ST, Fienup JR (2008) Efficient subpixel image registration algorithms. Opt Lett 33:156-158. CrossRef Medline

Guttman N, Kalish HI (1956) Discriminability and stimulus generalization. J Exp Psychol 51:79-88. CrossRef Medline
Ha TS, Smith DP (2006) A pheromone receptor mediates 11-cis-vaccenyl acetate-induced responses in Drosophila. J Neurosci 26:8727-8733. CrossRef Medline

Hanson HM (1959) Effects of discrimination training on stimulus generalization. J Exp Psychol 58:321-334. CrossRef Medline

Heisenberg M (2003) Mushroom body memoir: from maps to models. Nat Rev Neurosci 4:266-275. CrossRef Medline

Hellstern F, Malaka R, Hammer M (1998) Backward inhibitory learning in honeybees: a behavioral analysis of reinforcement processing. Learn Mem 4:429-444. CrossRef Medline

Honegger KS, Campbell RA, Turner GC (2011) Cellular-resolution population imaging reveals robust sparse coding in the Drosophila mushroom body. J Neurosci 31:11772-11785. CrossRef Medline

Itskov PM, Ribeiro C (2013) The dilemmas of the gourmet fly: the molecular and neuronal mechanisms of feeding and nutrient decision making in Drosophila. Front Neurosci 7:12. CrossRef Medline

Johnson BA, Xu Z, Ali SS, Leon M (2009) Spatial representations of odorants in olfactory bulbs of rats and mice: similarities and differences in chemotopic organization. J Comp Neurol 514:658-673. CrossRef Medline

Jones WD, Cayirlioglu P, Kadow IG, Vosshall LB (2007) Two chemosensory receptors together mediate carbon dioxide detection in Drosophila. Nature 445:86-90. CrossRef Medline

Kadohisa M, Wilson DA (2006) Separate encoding of identity and similarity of complex familiar odors in piriform cortex. Proc Natl Acad Sci U S A 103:15206-15211. CrossRef Medline

Kalman RE (1960) A new approach to linear filtering and prediction problems. J Basic Eng 82:35-45. CrossRef

Kitamoto T (2001) Conditional modification of behavior in Drosophila by targeted expression of a temperature-sensitive shibire allele in defined neurons. J Neurobiol 47:81-92. CrossRef Medline

Kreher SA, Mathew D, Kim J, Carlson JR (2008) Translation of sensory input into behavioral output via an olfactory system. Neuron 59:110-124. CrossRef Medline

Krishnan B, Dryer SE, Hardin PE (1999) Circadian rhythms in olfactory responses of Drosophila melanogaster. Nature 400:375-378. CrossRef Medline

Kurtovic A, Widmer A, Dickson BJ (2007) A single class of olfactory neurons mediates behavioural responses to a Drosophila sex pheromone. Nature 446:542-546. CrossRef Medline

Laissue PP, Reiter C, Hiesinger PR, Halter S, Fischbach KF, Stocker RF (1999) Three-dimensional reconstruction of the antennal lobe in Drosophila melanogaster. J Comp Neurol 405:543-552. CrossRef Medline

Li W, Howard JD, Parrish TB, Gottfried JA (2008) Aversive learning enhances perceptual and cortical discrimination of indiscriminable odor cues. Science 319:1842-1845. CrossRef Medline

Litaudon P, Mouly AM, Sullivan R, Gervais R, Cattarelli M (1997) Learning-induced changes in rat piriform cortex activity mapped using multisite recording with voltage sensitive dye. Eur J Neurosci 9:15931602. CrossRef Medline

Masek P, Heisenberg M (2008) Distinct memories of odor intensity and quality in Drosophila. Proc Natl Acad Sci U S A 105:15985-15990. CrossRef Medline

Meister M, Bonhoeffer T (2001) Tuning and topography in an odor map on the rat olfactory bulb. J Neurosci 21:1351-1360. Medline

Mishra D, Louis M, Gerber B (2010) Adaptive adjustment of the generalization-discrimination balance in larval Drosophila. J Neurogenet 24:168-175. CrossRef Medline

Murthy M, Fiete I, Laurent G (2008) Testing odor response stereotypy in the Drosophila mushroom body. Neuron 59:1009-1023. CrossRef Medline

Niewalda T, Völler T, Eschbach C, Ehmer J, Chou WC, Timme M, Fiala A, Gerber B (2011) A combined perceptual, physico-chemical, and imaging approach to 'odour-distances' suggests a categorizing function of the Drosophila antennal lobe. PLoS One 6:e24300. CrossRef Medline

Olsen SR, Wilson RI (2008) Lateral presynaptic inhibition mediates gain control in an olfactory circuit. Nature 452:956-960. CrossRef Medline

Parnas M, Lin AC, Huetteroth W, Miesenböck G (2013) Odor discrimination in Drosophila: from neural population codes to behavior. Neuron 79:932-944. CrossRef Medline

Pavlov IP (1927) Conditioned reflexes: an investigation of the physiological activity of the cerebral cortex. London: Oxford UP. 
Pearce JM (1994) Similarity and discrimination: a selective review and a connectionist model. Psychol Rev 101:587-607. CrossRef Medline

Pech U, Dipt S, Barth J, Singh P, Jauch M, Thum AS, Fiala A, Riemensperger T (2013) Mushroom body miscellanea: transgenic Drosophila strains expressing anatomical and physiological sensor proteins in Kenyon cells. Front Neural Circuits 7:147. CrossRef Medline

Qin H, Cressy M, Li W, Coravos JS, Izzi SA, Dubnau J (2012) Gamma neurons mediate dopaminergic input during aversive olfactory memory formation in Drosophila. Curr Biol 22:608-614. CrossRef Medline

Riemensperger T, Völler T, Stock P, Buchner E, Fiala A (2005) Punishment prediction by dopaminergic neurons in Drosophila. Curr Biol 15:19531960. CrossRef Medline

Riemensperger T, Pech U, Dipt S, Fiala A (2012) Optical calcium imaging in the nervous system of Drosophila melanogaster. Biochim Biophys Acta 1820:1169-1178. CrossRef Medline

Riveron J, Boto T, Alcorta E (2009) The effect of environmental temperature on olfactory perception in Drosophila melanogaster. J Insect Physiol 55:943-951. CrossRef Medline

Root CM, Masuyama K, Green DS, Enell LE, Nässel DR, Lee CH, Wang JW (2008) A presynaptic gain control mechanism fine-tunes olfactory behavior. Neuron 59:311-321. CrossRef Medline

Sachse S, Galizia CG (2002) Role of inhibition for temporal and spatial odor representation in olfactory output neurons: a calcium imaging study. J Neurophysiol 87:1106-1117. Medline

Sachse S, Rueckert E, Keller A, Okada R, Tanaka NK, Ito K, Vosshall LB (2007) Activity-dependent plasticity in an olfactory circuit. Neuron 56: 838-850. CrossRef Medline

Schwaerzel M, Heisenberg M, Zars T (2002) Extinction antagonizes olfactory memory at the subcellular level. Neuron 35:951-960. CrossRef Medline

Seki Y, Rybak J, Wicher D, Sachse S, Hansson BS (2010) Physiological and morphological characterization of local interneurons in the Drosophila antennal lobe. J Neurophysiol 104:1007-1019. CrossRef Medline

Shepard RN (1987) Toward a universal law of generalization for psychological science. Science 237:1317-1323. CrossRef Medline

Sosulski DL, Bloom ML, Cutforth T, Axel R, Datta SR (2011) Distinct representations of olfactory information in different cortical centres. Nature 472:213-216. CrossRef Medline

Stensmyr MC, Dweck HK, Farhan A, Ibba I, Strutz A, Mukunda L, Linz J, Grabe V, Steck K, Lavista-Llanos S, Wicher D, Sachse S, Knaden M, Becher PG, Seki Y, Hansson BS (2012) A conserved dedicated olfactory circuit for detecting harmful microbes in Drosophila. Cell 151:1345-1357. CrossRef Medline

Stettler DD, Axel R (2009) Representations of odor in the piriform cortex. Neuron 63:854-864. CrossRef Medline

Stocker RF, Heimbeck G, Gendre N, de Belle JS (1997) Neuroblast ablation in Drosophila P[GAL4] lines reveals origins of olfactory interneurons. J Neurobiol 32:443-456. CrossRef Medline

Stopfer M, Bhagavan S, Smith BH, Laurent G (1997) Impaired odour discrimination on desynchronization of odour-encoding neural assemblies. Nature 390:70-74. CrossRef Medline

Suh GS, Wong AM, Hergarden AC, Wang JW, Simon AF, Benzer S, Axel R, Anderson DJ (2004) A single population of olfactory sensory neurons mediates an innate avoidance behaviour in Drosophila. Nature 431:854859. CrossRef Medline

Suh GS, Ben-Tabou de Leon S, Tanimoto H, Fiala A, Benzer S, Anderson DJ (2007) Light activation of an innate olfactory avoidance response in Drosophila. Curr Biol 17:905-908. CrossRef Medline

Szyszka P, Demmler C, Oemisch M, Sommer L, Biergans S, Birnbach B, Silbering AF, Galizia CG (2011) Mind the gap: olfactory trace conditioning in honeybees. J Neurosci 31:7229-7239. CrossRef Medline
Tanaka NK, Awasaki T, Shimada T, Ito K (2004) Integration of chemosensory pathways in the Drosophila second-order olfactory centers. Curr Biol 14:449-457. CrossRef Medline

Tanaka NK, Ito K, Stopfer M (2009) Odor-evoked neural oscillations in Drosophila are mediated by widely branching interneurons. J Neurosci 29:8595-8603. CrossRef Medline

Tanimoto H, Heisenberg M, Gerber B (2004) Experimental psychology: event timing turns punishment to reward. Nature 430:983. CrossRef Medline

Thévenaz P, Ruttimann UE, Unser M (1998) A pyramid approach to subpixel registration based on intensity. IEEE Trans Image Process 7:27-41. CrossRef Medline

Tian L, Hires SA, Mao T, Huber D, Chiappe ME, Chalasani SH, Petreanu L, Akerboom J, McKinney SA, Schreiter ER, Bargmann CI, Jayaraman V, Svoboda K, Looger LL (2009) Imaging neural activity in worms, flies and mice with improved GCaMP calcium indicators. Nat Methods 6:875881. CrossRef Medline

Tully T, Quinn WG (1985) Classical conditioning and retention in normal and mutant Drosophila melanogaster. J Comp Physiol A Neuroethol Sens Neural Behav Physiol 157:263-277. CrossRef Medline

Turner GC, Bazhenov M, Laurent G (2008) Olfactory representations by Drosophila mushroom body neurons. J Neurophysiol 99:734-746. CrossRef Medline

Vosshall LB, Stocker RF (2007) Molecular architecture of smell and taste in Drosophila. Annu Rev Neurosci 30:505-533. CrossRef Medline

Wagh DA, Rasse TM, Asan E, Hofbauer A, Schwenkert I, Dürrbeck H, Buchner S, Dabauvalle MC, Schmidt M, Qin G, Wichmann C, Kittel R, Sigrist SJ, Buchner E (2006) Bruchpilot, a protein with homology to ELKS/ CAST, is required for structural integrity and function of synaptic active zones in Drosophila. Neuron 49:833-844. CrossRef Medline

Wang JW, Wong AM, Flores J, Vosshall LB, Axel R (2003) Two-photon calcium imaging reveals an odor-evoked map of activity in the fly brain. Cell 112:271-282. CrossRef Medline

Wang Y, Mamiya A, Chiang AS, Zhong Y (2008) Imaging of an early memory trace in the Drosophila mushroom body. J Neurosci 28:4368-4376. CrossRef Medline

Williams BA (2002) Behavioral contrast redux. Anim Learn Behav 30:1-20. CrossRef Medline

Wilson DA, Stevenson RJ (2006) Learning to smell. Baltimore: Johns Hopkins UP.

Wilson RI, Laurent G (2005) Role of GABAergic inhibition in shaping odorevoked spatiotemporal patterns in the Drosophila antennal lobe. J Neurosci 25:9069-9079. CrossRef Medline

Wilson RI, Turner GC, Laurent G (2004) Transformation of olfactory representations in the Drosophila antennal lobe. Science 303:366-370. CrossRef Medline

Yarali A, Ehser S, Hapil FZ, Huang J, Gerber B (2009) Odour intensity learning in fruit flies. Proc Biol Sci 276:3413-3420. CrossRef Medline

Young JM, Wessnitzer J, Armstrong JD, Webb B (2011) Elemental and nonelemental olfactory learning in Drosophila. Neurobiol Learn Mem 96: 339-352. CrossRef Medline

Youngentob SL, Johnson BA, Leon M, Sheehe PR, Kent PF (2006) Predicting odorant quality perceptions from multidimensional scaling of olfactory bulb glomerular activity patterns. Behav Neurosci 120:1337-1345. CrossRef Medline

Yu D, Ponomarev A, Davis RL (2004) Altered representation of the spatial code for odors after olfactory classical conditioning: memory trace formation by synaptic recruitment. Neuron 42:437-449. CrossRef Medline

Zars T, Fischer M, Schulz R, Heisenberg M (2000) Localization of a shortterm memory in Drosophila. Science 288:672-675. CrossRef Medline 